\title{
Caracteres sedimentológicos, geoquímicos y cronológicos de la Formación Puncosvicana en las Sierras de Palermo, Cachi y Molinos. Cordillera Oriental, Argentina
}

\author{
Sedimentological, geochemical and chronological characteristics \\ of Puncoviscana Formation in Palermo, Cachi and Molinos ranges. \\ Eastern Cordillera, Argentina
}

\footnotetext{
Hubert MILLER'; Anette LORK'; Alejandro J. TOSELLI; Florencio G. ACEÑOLAZA²

1 Department für Geo- und Umweltwissenschaften, Luisenstrasse 37, D-80333, Munich, Germany.

2 INSUGEO, CONICET-UNT. E-mail: insugeohm@tucbbs.com.ar. Miguel Lillo 205, (4000) S. M. de Tucumán, Argentina.
}

\section{RESUMEN}

Las sierras de Palermo, Cachi y Molinos, de la provincia de Salta, forman parte de la Cordillera Oriental, que está integrada por un basamento meta-sedimentario que se asigna a la Formación Puncoviscana, con edad de sedimentación y leptometamorfismo que corresponde al lapso Ediacarano-Terreneuviano. Las psamitas y pelitas están representadas esencialmente por grauvacas, litarenitas, lutitas y wackes, las cuales se habrían depositado en ambientes de arco de islas continental a margen continental activo. Las áreas de proveniencia habrían estado constituidas esencialmente por sedimentos cuarzosos y rocas ígneas félsicas a intermedias, que son típicas de la Corteza Continental Superior (UCC), las cuales habrían sufrido transporte hidráulico relativamente breve que permitió su alteración pero no una selección granulométrica eficiente. Las edades y caracteres morfológicos de los circones detríticos evidencian distintos orígenes y edades, unos volcánicos euhedrales de $527 \mathrm{Ma}$ y otros redondeados por erosión con edades de $583 \mathrm{Ma}$. Las trazas fósiles correspondientes a las asociaciones de Nereites saltensis que se desarrollan, son cohe-

\footnotetext{
- Ref. bibliográfica: Miller, H.; Lork, A.; Toselli, A. J.; Aceñolaza, F. G. 2019. "Caracteres sedimentológicos, geoquímicos y cronológicos de la Formación Puncosvicana en las Sierras de Palermo, Cachi y Molinos. Cordillera Oriental, Argentina". Acta geológica lilloana 31 (1): 1-34. Fundación Miguel Lillo, Tucumán, Argentina. D.O.I.: https://doi.org/10.30550/j.agl/2019.31.1/1 > Recibido: 24/07/18 - Aceptado: 17/02/19 > URL de la revista: http://actageologica.lillo.org.ar

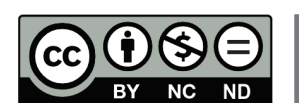

open $\bigcirc$ Access

> Algunos derechos reservados. Esta obra está bajo una Licencia Creative Commons Atribución - No Comercial - Sin Obra Derivada 4.0 Internacional.
} 
rentes con las edades $>540 \mathrm{Ma}$ obtenidas a partir de los circones, mientras que no se encontró hasta ahora en esta región Oldhamia radiata. La Formación Puncoviscana,es afectada con posterioridad, por un evento metamórfico regional que culmina con la orogenia Tilcárica ( $520 \mathrm{Ma})$, que desarrolla condiciones de Facies Sub-esquistos Verdes alcanzando eventualmente Facies Esquistos Verdes. Otro evento dinámicotérmico posterior ocurre entre los 488 y $453 \mathrm{Ma}$ (Cámbrico superior - Ordovícico superior) que da lugar a la intrusión de los plutones tonalítico-trondhjemíticos y granodiorítico-graníticos de la Formación Cachi, con los que se asocian los gneises, migmatitas, filitas y esquistos moteados del Complejo La Paya, en Facies de Anfibolitas a Granulitas. Dichas edades U-Pb fueron determinadas en circones y monacitas, como así también mediante los isótopos de estroncio.

Palabras clave - Ciclos Pampeano/Famatiniano. Edades isotópicas y trazas fósiles. Áreas de proveniencia y caracteres sedimentarios. Metamorfismo.

\section{ABSTRACT}

Palermo, Cachi and Molinos ranges, of Salta province, are part of the Eastern Cordillera, which is composed of a meta-sedimentary basement assigned to the Puncoviscana Formation, with an age of sedimentation and lepto-metamorphism that corresponding to the Ediacaran-Terreneuvian. The psammites and pelites are represented essentially by greywackes, litharenites, shales and wackes, which would have been deposited in a continental island-arc to an active continental margin. The area source would have been constituted essentially by siliceous sediments and felsic to intermediate igneous rocks, typical of Upper Continental Crust (UCC) that would have undergone relatively brief hydraulic transport that allowed its alteration but not an efficient granulometric selection. The ages and morphological characters of detrital zircons show different origins and ages, euhedral volcanic ones of $527 \mathrm{My}$ and others rounded by erosion with ages of $583 \mathrm{My}$. The fossil traces corresponding to the associations of Nereites saltensis, which one is coherent with the deposition ages of $>540$ My obtained in detrital zircons, and the levels of Oldhamia radiate with ages $<540 \mathrm{My}$ is not observed in these mountains. The Puncoviscana Formation is subsequently affected by a regional metamorphic event that culminates with the Tilcárica orogeny ( $\sim 520 \mathrm{My}$ ), which develops conditions of Sub-Green Schist Facies eventually reaching Green-Schist Facies. Another posterior tectonic-thermal event occurs between 488 and

$453 \mathrm{My}$ (Upper Cambrian - Upper Ordovician) that produce the intrusion of the tonalitic-trondhjemitic and granodioritic-granitic plutons of the Cachi Formation, with which the gneisses and migmatites are associated to phyllites and spotted schists of La Paya Complex, in Amphibolite and Granulite Facies. The U-Pb ages were in zircons and monazites determined the sedimentation epoch, as well as by the strontium isotopes. 


\section{INTRODUCCIÓN, UBICACIÓN Y OBJETIVOS}

Las sierras de Palermo, Cachi y Molinos se ubican en la provincia de Salta, en el NO de Argentina, en el ámbito de la Cordillera Oriental y están constituidos esencialmente por basamento metamórfico-ígneo, que está representado por las meta-sedimentitas de la Formación Puncoviscana depositadas en el lapso Ediacarano-Terreneuviano, las cuales fueron intruidas por los plutones Ordovícicos de la Formación Cachi, que a su vez están incluidos dentro de las metamorfitas del Complejo La Paya, que se generan coetáneamente con estos intrusivos.

La región estudiada cubre los faldeos orientales de las mencionadas sierras hasta el valle Calchaquí, afloramientos situados al oeste de la $\mathrm{RN} 40$ que constituye su límite oriental. El sector está comprendido entre un poco al $\mathrm{N}$ de la localidad de La Poma, hasta la zona de La Angostura, a lo largo de aproximadamente $100 \mathrm{~km}$, en dirección N-S, entre las latitudes $24^{\circ} 40^{\prime}$ a $25^{\circ} 30^{\prime}$ S (Fig. 1).

Uno de los objetivos importantes a alcanzar con este estudio es elaborar una secuencia temporal de los eventos geológicos de la región, a fin de reconstruir la evolución sedimentario-metamórfica del basamento de los Andes Centrales en el noroeste argentino. Para ello se utilizan las múltiples evidencias paleo-ambientales y estratigráficas, apoyadas con las edades aportadas por las asociaciones de trazas fósiles, junto a edades isotópicas de circones y monacitas, además de los datos geoquímicos y las relaciones de los isótopos de $\mathrm{Sr}$ y $\mathrm{Rb}$, que se usan para interpretar las litologías estudiadas.

Asimismo, se pretende interpretar la composición de las áreas de proveniencia de los sedimentos, así como el ambiente de deposición de los mismos, utilizando los análisis químicos de elementos mayores, menores y trazas, así como sus interrelaciones. A estos aspectos de la investigación se agregan las determinaciones mineralógicas mediante microscopía tradicional, microsonda y difracción de rayos-X, que se complementan con los datos petrográficos relacionados con las texturas desarrolladas.

En las determinaciones geocronológicas, se utilizan las relaciones de isótopos $\mathrm{U}-\mathrm{Pb}$ en circones y monacitas, con el apoyo de isótopos de estroncio e isócronas $\mathrm{Rb}-\mathrm{Sr}$, los cuales permiten establecer las edades de las rocas metamórficas y de los cuerpos que las intruyen.

\section{ENTORNO GEOLÓGICO Y ANTECEDENTES}

Las sierras de Palermo, Cachi y Molinos han sido largamente estudiadas en sus aspectos estratigráficos. Su unidad más antigua es el basamento metamórfico que está representado por la Formación Puncoviscana, nombre acuñado por Turner (1960) en la sierra de Santa Victoria y posteriormente utilizado también para todo el basamento meta-sedimentario de la Cordillera Oriental (Turner, 1972). El término Formación La Paya fue asignado por Aceñolaza y Toselli (1976) y aplicado al conjunto litológico formado por esquistos moteados, gneises y migmatitas, productos del mayor metamorfismo, que transformó los sedimentos de la Formación Puncoviscana. Esta heterogeneidad litológica llevó a que Toselli y Rossi de Toselli (1990a-b) 


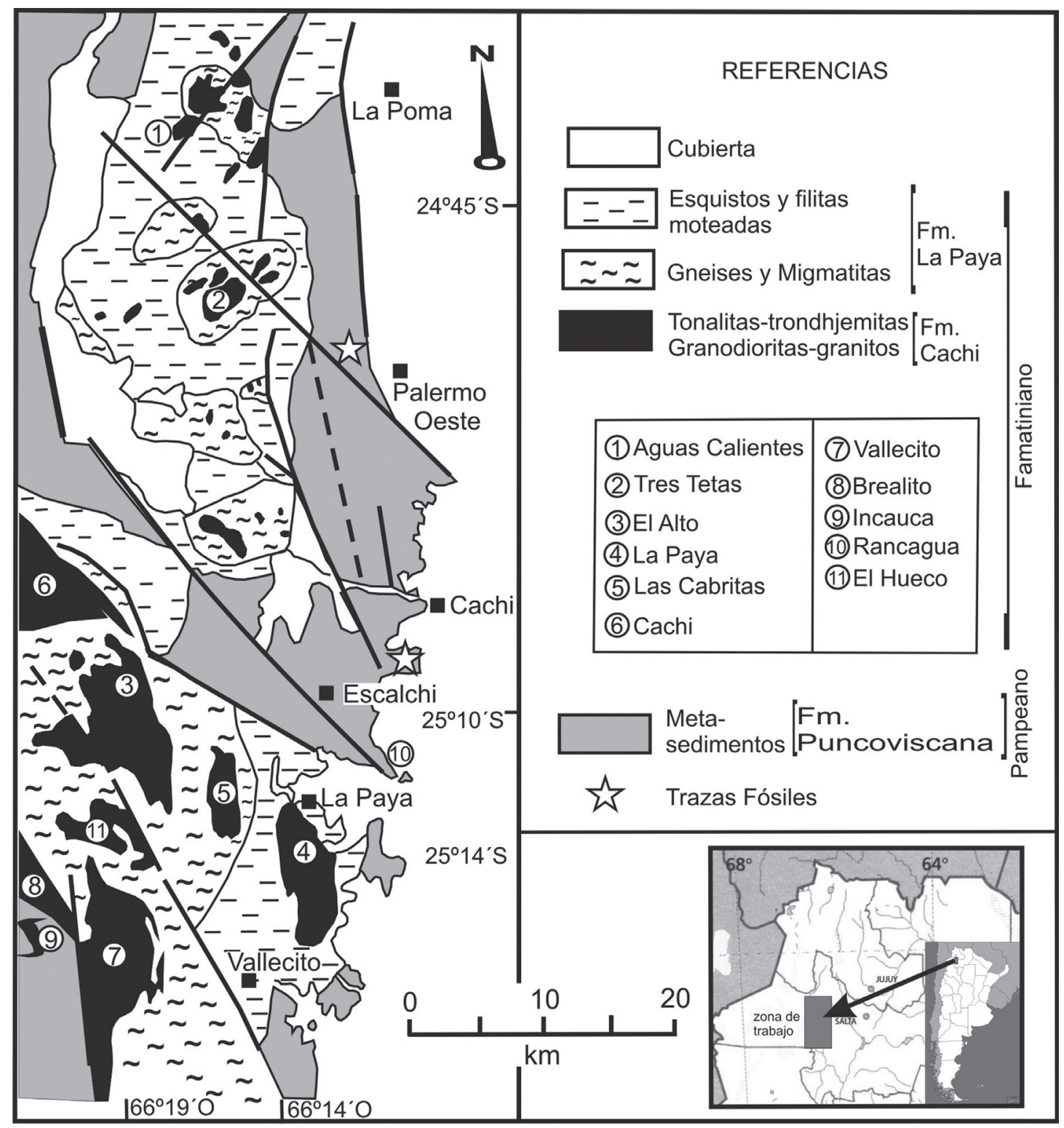

Fig. 1. Mapa geológico de un sector de la Cordillera Oriental, indicando los puntos fosilíferos y áreas datadas de la Formación Puncoviscana, con su situación geográfica en el NO de Argentina.

la rebautizaran como Complejo La Paya. Finalmente a los intrusivos plutónicos, de edad ordovícica que intruyen a las metamorfitas, son agrupados con el nombre de Formación Cachi (Aceñolaza y Toselli, 1976).

Entre los autores que trabajaron intensamente en esta comarca deben mencionarse: Turner y Mon (1979); Omarini et al. (1985); Moya y Salfity (1982); Salfity et al. (1975); Ježek (1990); Mon y Hongn (1988, 1996); Mon et al. (2017); Méndez et al. (2006); etc.). Mientras que los aspectos geocronológicos fueron desarrollados entre otros por Halpern y Latorre (1973); Borrello (1969, 1971); Galliski (1983); Aceñolaza y Toselli (1981); Lork y Bahlburg (1993); Coira et al. (1990); Hongn y Seggiaro (2001); Sola et al. (2006); López de Azarevich et al. (2012); Aceñolaza (2012); Hauser (2011), Miller et al. (2010). 
En la región estudiada, el Ciclo Pampeano es representado por la Formación Puncoviscana, cuyos caracteres serán desarrollados más adelante.

El Ciclo Famatiniano está representado por el Complejo La Paya y la Formación Cachi. El Complejo La Paya está integrado por dos grupos litológicos diferentes. Uno, constituido por filitas moteadas, esquistos moteados y esquistos nodularesJos cuales se formaron por efecto térmico a partir de las rocas de la Formación Puncoviscana; a estos se agregan los gneises y migmatitas, cuya génesis habría tenido lugar en niveles de deformación más profundos (Toselli y Rossi de Toselli, 1990a-b).

Los esquistos y filitas moteadas y nodulares se formaron, por efecto térmico de los intrusivos sobre las rocas de la Formación Puncoviscana. En general, son de colores grises a verdosos con brillo satinado y conservan aún cierta estratificación original. Son rocas cuarzo-micáceos con motas y nódulos de clorita, biotita y cordierita, con desarrollo de esquistosidad bien definida. Adams et al. $(1989,1990)$ obtuvieron edades K-Ar sobre roca total, del metamorfismo de muy bajo grado (rango clorita) relacionado con las intrusiones de 451 - 472 Ma, en el área de Rancagua.

Los gneises y migmatitas se desarrollan regionalmente en las inmediaciones, envolviendo a los plutones intrusivos. Se caracterizan por sus colores claros y composición cuarzo-feldespáticas. Poseen desarrollo marcado de bandeado composicional cuarzo-felsdespático, conteniendo con frecuencia nódulos de cordierita junto a la biotita dominante, plagioclasa, cuarzo y moscovita.

Sola et al. (2010) estudian el leucogranito sintectónico Pumayaco, producto de anatexis cortical en el extremo norte de la Sierra de Molinos como integrante del Complejo La Paya. Determinan mediante diagramas concordia en circones la edad de 466,5+/-3 Ma, que también corresponde a la diatexita de la cual forma parte. Los resultados son coherentes con los valores obtenidos por Lork et al. (1989) en el granito La Angostura mediante circones de 453+25/-27 Ma y en monacitas de $462+/-1$ Ma.

El conjunto ígneo-metamórfico se habría formado en respuesta al ascenso de domos de diatexitas de origen profundo, asociados con fuertes deformaciones localizadas, pero con evoluciones genéticas diferentes de los fundidos originales, unos con caracteres tonalítico-trondhjemíticos y otros granodiorítico-graníticos.

El nombre de Formación Cachi fue acuñado, por Turner (1960) para caracterizar a los intrusivos de los Nevados de Palermo y de Cachi, a los que asignó edad precámbrica, tesitura mantenida por Mon et al. (2017) aunque diversos autores, utilizando diferentes metodologías geocronológicas demuestran que los mismos intruyeron y cristalizaron en el Ordovícico. Esta formación, como bien se sabe, está constituida por dos grupos ígneos: uno representado por trondhjemitas-tonalitas, y otro por granitos-granodioritas, que definen dos suites magmáticas.

La naturaleza y edad de las trondhjemitas de las sierras de Cachi, Palermo y Molinos, fueron investigadas por Galliski (1983), Galliski y Miller (1989); Galliski et al. (1990); Cisterna (1986); Lork et al. (1989); Schön y Miller (1989); Schön (1991); Lork y Bahlburg (1993), y Méndez et al. (2006). Las mismas se inyectan en las metamorfitas de bajo grado y genéticamente se asociarían con el mismo evento tectónico-metamórfico que generó al Complejo La Paya. 
Los caracteres mineralógico-petrográficos y geoquímicos de las rocas granítico-graníticas, evidencian que sus orígenes se habrían relacionado con anomalías en el manto y fusión cortical parcial, que habrían controlado la formación de la suite calco-alcalina alta en potasio, para las granodioritas-granitos, diferente a la tonalítica-trondhjemítica, que es alta en sodio (Galliski, 1983). Ambas formadas en un mismo ambiente geotectónico de arco volcánico, o de margen continental activo, con caracteres distensivos o transtensivos (Galliski et al. 1990).

\section{CARACTERES GEOLÓGICOS DE LA FORMACIÓN PUNCOVISCANA}

La Formación Puncoviscana, está constituida por rocas meta-sedimentarias silico-clásticas pelíticas y psamíticas con baja madurez. Las mismas se habrían originado en respuesta a un transporte sedimentario relativamente breve sin procesos mayores de reciclaje, que no permitió maduración del material sedimentario, ni alteración avanzada, que se refleja en los clastos de feldespatos relativamente frescos. En general las rocas de esta formación son de grano medio a fino y están pobremente seleccionadas, con altos contenidos de matriz, que hacen difícil realizar la cuantificación de los minerales constituyentes utilizando los métodos petrográficos microscópicos clásicos pero, sus caracteres petrográficos particulares, llevaron a que su caracterización se realice esencialmente utilizando diagramas geoquímicos y difracción de rayos-X.

Esporádicamente en la secuencia estratigráfica, se desarrollan niveles de diamictitas en las localidades de Escalchi, Seclantás y Molinos, que fueron interpretados por Ježek et al. (1985); Durand y Spalletti (1986); Spalletti y Durand (1986); Durand (1990), etc., como depósitos psefíticos formados en cañones submarinos.

La secuencia sedimentaria de la Formación Puncoviscana ha sido modificada por fenómenos térmico-deformativos, desarrollando distintas asociaciones de rocas metamórficas correspondientes al Complejo La Paya. Omarini y Alonso (1987) describen la presencia de niveles de vulcanitas intercaladas en la secuencia silicoclástica al NE de Cachi. Otros delgados niveles de tobas con importante contenido en circones detríticos con diferentes orígenes fueron datados por Lork et al. (1990) que en la zona de Rancagua, donde obtienen, una edad U-Pb promedio de $583 \mathrm{Ma}$ en circones de diferentes granulometrías, con colores variados y formas redondeadas por el transporte; mientras que en el área de Las Cabritas obtuvieron un promedio de $527 \mathrm{Ma}$ en circones prismáticos euhedrales de origen volcanogénico. Las edades discordantes que presentan algunos circones pueden ser atribuidas a un evento metamórfico previo que produjo la perdida diferencial de plomo según las granulometrías. Asimismo, Lork et al. (1990) mediante un modelado genético obtuvieron una edad modelo de $558 \mathrm{Ma}$, que son coherentes con las edades de 540-560 Ma obtenidos para diferentes localidades de afloramiento de la Formación Puncoviscana.

Por otra parte, los trabajos realizados sobre las trazas fósiles encontradas en diversas localidades de esta formación permiten considerarla como representativa del lapso Ediacarano-Terreneuviano, en base a los hallazgos de asociaciones de Nereites saltensis por Durand y Aceñolaza (1990); Aceñolaza y Aceñolaza (2005) y López de 
Azarevich et al. (2012); mientras que no se ha encontrado aún a Oldhamia radiata, en estas sierras.

\section{PETROGRAFÍA Y MINERALOGIA DE LA FORMACIÓN PUNCOVISCANA}

Las rocas sedimentarias clásticas originales que constituyen a la Formación Puncoviscana en estas sierras, fueron interpretadas genéticamente por Ježek y Miller (1986) y Ježek (1990) como resultantes de secuencias sedimentarias poli-cíclicas depositadas en un ambiente distensivo, estando caracterizadas por cuarzo dominante, con feldespatos y litoclastos volcánicos y sedimentarios angulosos, así como por material limo-arcilloso, que indican baja selección, junto a relativamente corto transporte y rápido soterramiento.

Dichos caracteres petrográficos fueron interpretados por Zimmermann (2005) como correspondientes a una cuenca de antepaís, que no permite en general, la maduración de los sedimentos. Nosotros venimos considerando que dichos caracteres petrográficos se corresponden claramente con este ambiente que evidencia la culminación de la evolución de la cuenca que se inició como ambiente distensivo, luego compresivo con subducción y culminó como cuenca de antepaís, con la deposición de los sedimentos típicos mencionados (Toselli et al., 2017a, b).

La morfología de los circones euhedrales detríticos y magmáticos permitió siguiendo la metodología de Pupin (1980), establecer sus diferentes proveniencias, tanto profundas como superficiales, que se relacionan con los caracteres petrográficos y geoquímicos de los cuerpos ígneos en los cuales se forman (Fig. 2). Así tenemos un grupo importante de circones que pertenecen a granitoides aluminosos, de origen cortical anatéctico. Otros circones se asignan a granitoides calco-alcalinos y alcalinos, de origen híbrido por interacción entre rocas de origen mantélico, con material cortical. Los circones que derivarían de tonalitas se forman en niveles más profundos, con participación de material de manto. Los puntos negros de la figura indican los circones idiomorfos detríticos marrones obtenidos de Rancagua; mientras que los puntos blancos corresponden a circones idiomorfos magmáticos logrados en Rancagua, La Paya y El Brealito.

Las rocas pelíticas en general presentan un clivaje de crenulación oblicua a la estratificación original y que en general es de tipo penetrativo. Los minerales pelíticos que se identifican por difractometría de rayos-X son: illita, con índices de cristalinidad relativa entre ICR =116 y 197 (Fig. 3), según la técnica de Weber (1972) los cuales son similares a los valores registrados en la quebrada de Humahuaca (Toselli y Weber, 1982). La clorita, que localmente alcanza tamaño considerable, llega a definir una fábrica moteada, pero generalmente es de grano fino y está finamente dispersa en la masa de las rocas. Los picos de difracción de rayos-X permiten establecer que son ricas en hierro. Ópticamente muestran carácter biáxico positivo, con $2 \mathrm{~V}$ muy pequeño y pleocroísmo que varía de verde claro casi incoloro, a verde oscuro. Las esmectitas se identifican, en los diagramas de rayos-X, por un pico ancho, sin ningún máximo claro a aproximadamente $12 \AA$ y al ser calentada a $\sim 180^{\circ} \mathrm{C}$, colapsa a $10 \AA$. 


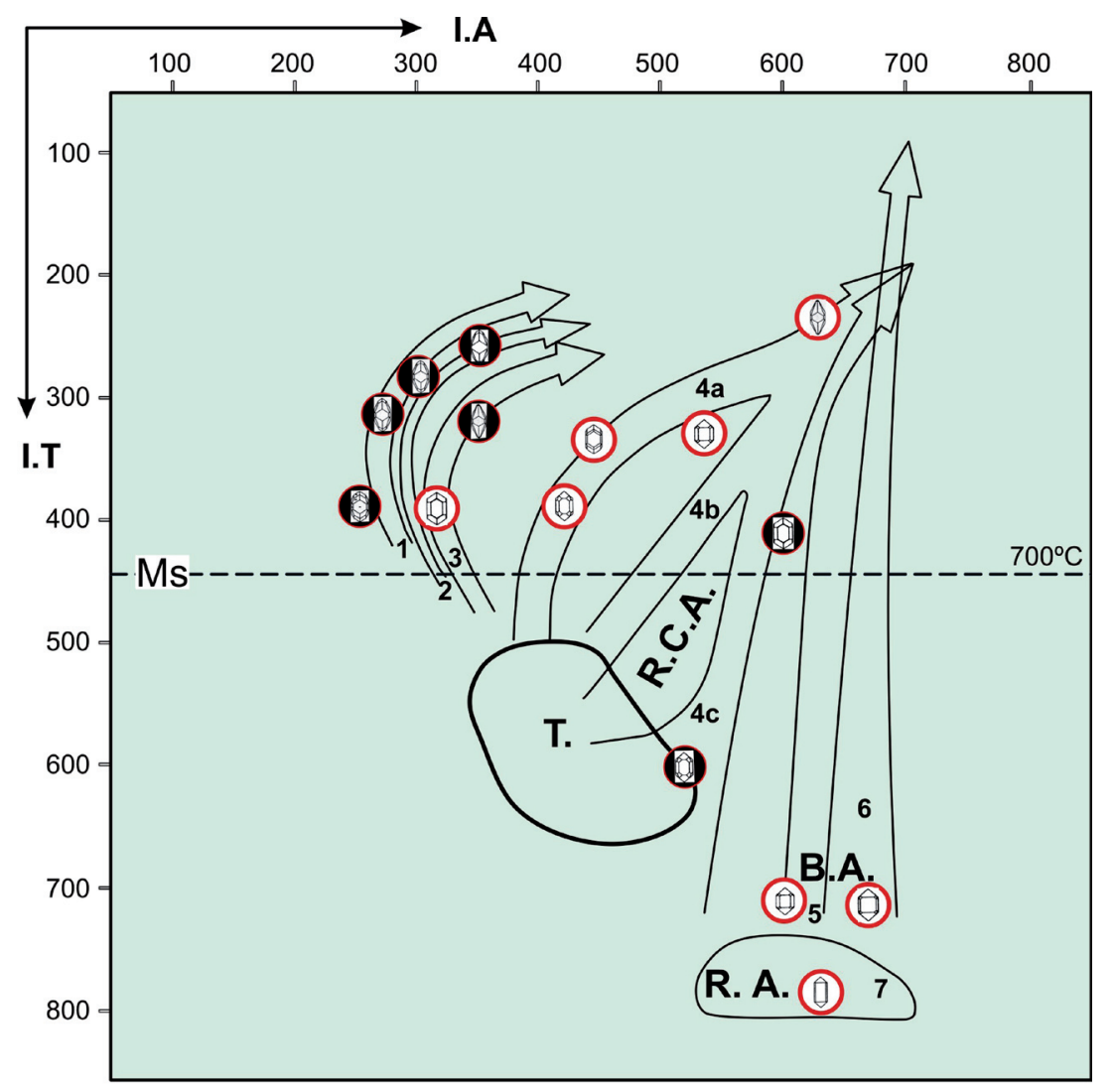

Fig. 2. Distribución de las poblaciones de circones de Pupin (1980). Granitoides anatécticos aluminosos de origen cortical, distribuidos en: 1) Leucogranitos aluminosos. 2) Monzogranitos y granodioritas sub-(autóctonos). 3) Monzo-granitos y granodioritas aluminosas. 4a, b, c: Series de granitoides calco-alcalinos, de origen híbrido cortical + manto. 5) Series de granitos sub-alcalinos. 6) Granitos de series alcalinas. 7) Series de granitos tholeíticos. Ms - límite de estabilidad de la moscovita en los granitos (I.T. $<450,750^{\circ} \mathrm{C}$ ). B.A.: basaltos alcalinos. R.A.: complejos de riolitas alcalinas. R.C.A.: complejos de riolitas calco-alcalinas. T: Tonalitas, con participación de material mantélico (puntos negros) - circones idiomorfos detríticos marrones (Rancagua). (puntos blancos) - circones idiomorfos magmáticos (Rancagua, La Paya y Brealito).

La biotita se presenta solamente en algunas muestras como pequeñas laminillas finamente dispersas en la masa de la roca, que sólo se identifican al microscopio. Esta se hace común en la zona externa de las aureolas de metamorfismo de contacto en su pasaje a las pizarras y filitas de la Formación Puncoviscana.

Otros minerales que están presentes en todas las muestras son el cuarzo y la magnetita. La albita está presente en granos pequeños, presentando el típico maclado polisintético. También se encuentran, aunque en forma aislada, material carbonoso y calcita. La asociación mineralógica y la cristalinidad relativa de la illita, indican que en estas rocas se han formado en condiciones de baja temperatura, que corresponde a la Facies Sub-esquistos Verdes y sólo localmente alcanzan la Facies Esquistos Verdes.

Esta formación presenta deformaciones tectónicas de diferentes intensidades y características, que no permiten establecer con seguridad los espesores reales de las secuencias meta-sedimentarias. 


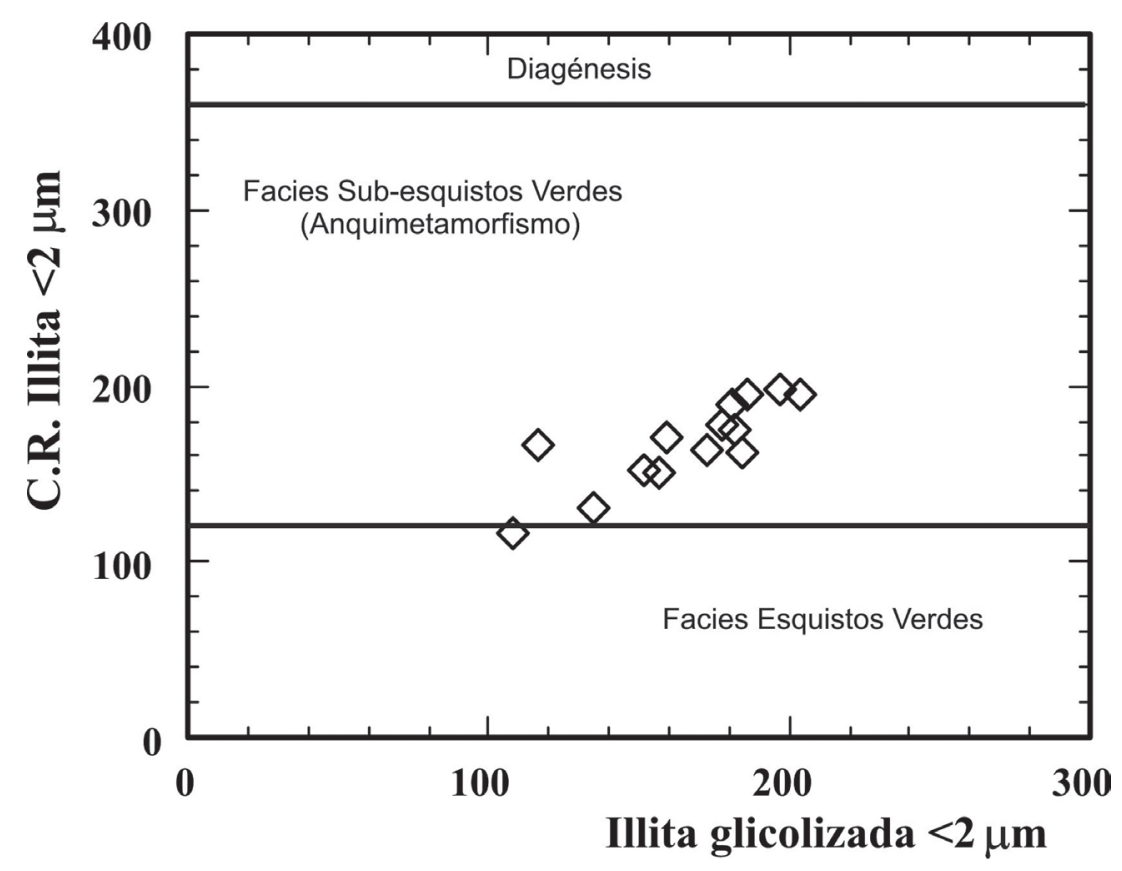

Fig. 3. Diagrama de cristalinidad relativa de illita (CRI), con valores que se proyectan en el campo de Facies Sub-esquistos Verdes (o anqui-metamorfismo) (Weber, 1972).

\section{CARACTERES QUÍMICOS DE LOS META-SEDIMENTOS}

Los análisis químicos de elementos mayores, menores y trazas utilizados en este trabajo, fueron realizados en el laboratorio de geoquímica de la Geowissenchaftlichen Fakultät de la Universidad Ludwig-Maximilians, de Munich. También se incluyen datos obtenidos de los trabajos publicados por Schön (1991) con referencias obligadas a las publicaciones realizadas por von Gosen et al. (2009); Zimmermann (2005); Keppie y Balhburg (1999) y Toselli et al. (2017b), los que en muchos casos son utilizados como patrones de comparación. Se trabajó con treinta y seis (36) muestras de elementos mayores, menores y trazas, cuyos resultados están expresados en las Tablas 1 y 2.

Para caracterizar a la Formación Puncoviscana se utilizaron, para las rocas psamíticas, diferentes diagramas como el de Pettijohn et al. (1972), el cual relaciona el $\log \left(\mathrm{Na}_{2} \mathrm{O} / \mathrm{K}_{2} \mathrm{O}\right)$ versus $\log \left(\mathrm{SiO}_{2} / \mathrm{Al}_{2} \mathrm{O} 3\right)$. Las muestras de las localidades estudiadas se proyectan en los campos de las grauvacas a litarenitas (Fig. 4A). El diagrama de Herron (1988), que se aplica a las psamitas y pelitas, usa como parámetros las relaciones entre $\log \left(\mathrm{Fe}_{2} \mathrm{O}_{3} / \mathrm{K}_{2} \mathrm{O}\right)$ versus. $\log \left(\mathrm{SiO}_{2} / \mathrm{Al}_{2} \mathrm{O}_{3}\right)$. Los parámetros corresponden a lutitas y waques, que gradan a litarenitas y sub-litarenitas (Fig. 4B). Los valores de las relaciones químicas utilizadas en los cálculos, se dan en la Tabla 1. 
要

$\frac{\pi}{\frac{\pi}{2}}$ $\underline{\tilde{\sigma}}$ ᄃ

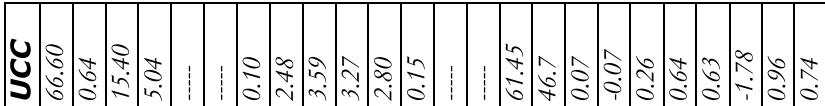

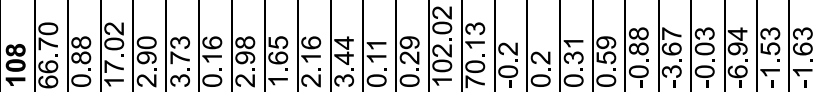
- o o - n m 0 n

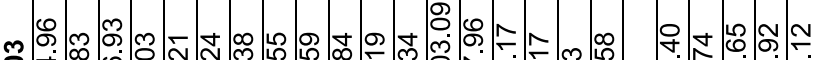

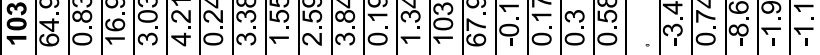
急

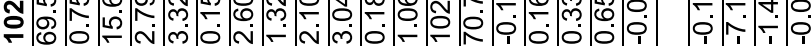

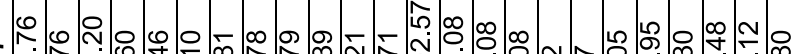

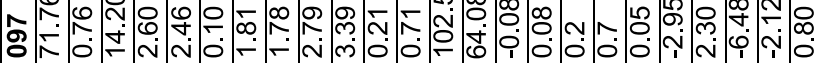
D

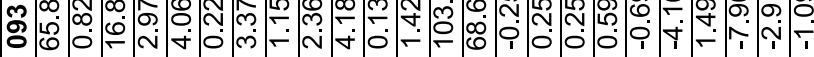

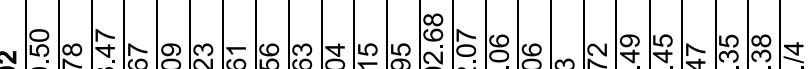

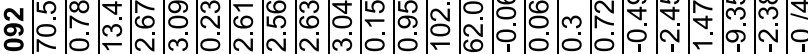

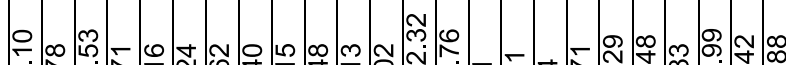

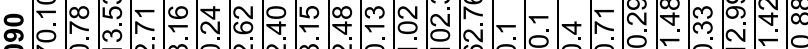

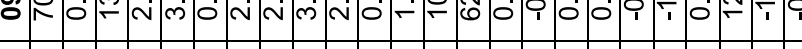

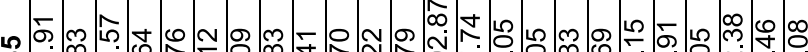

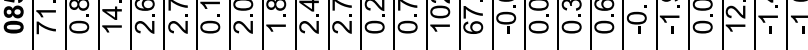

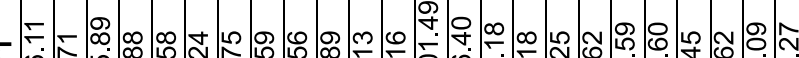

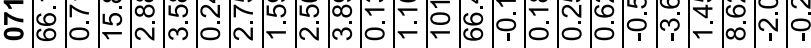

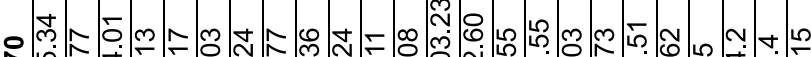

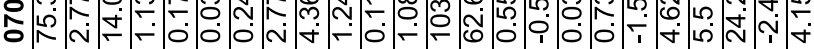

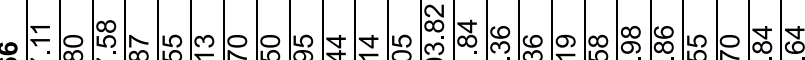

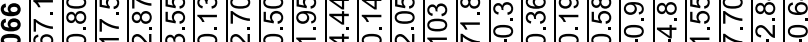

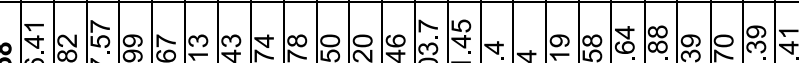

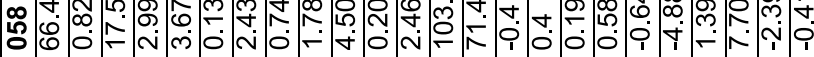
穴

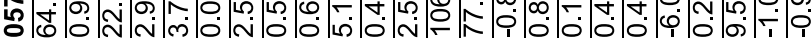

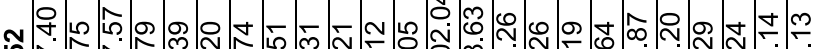

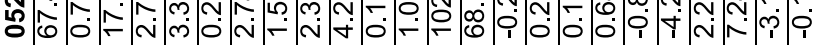
仹 范

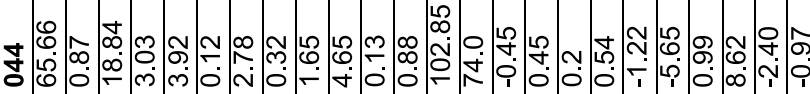

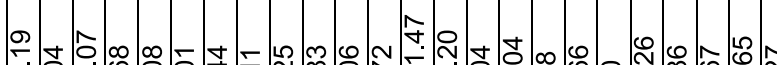
-

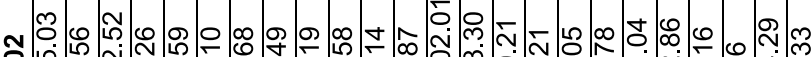

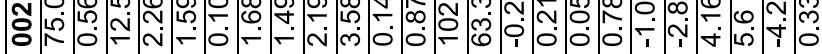
管 


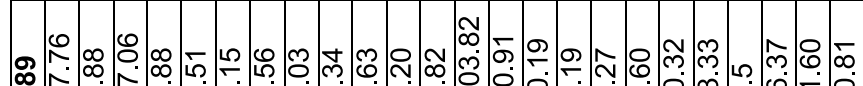

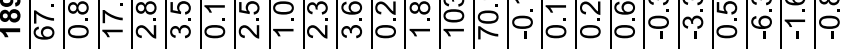

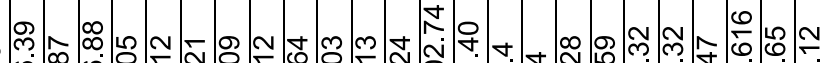

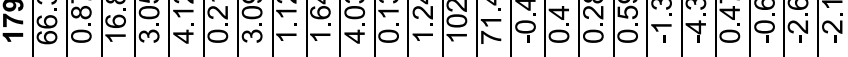

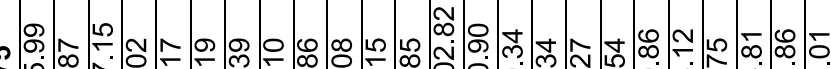

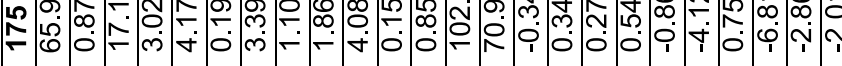

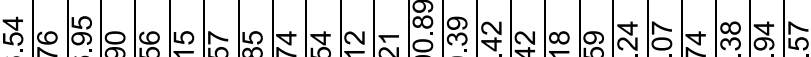

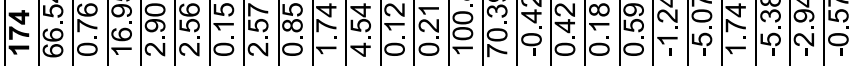

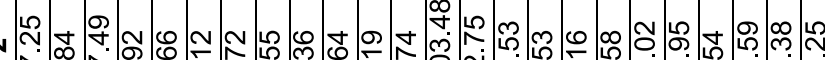

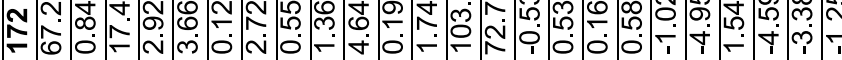
m.

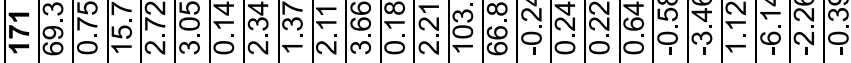

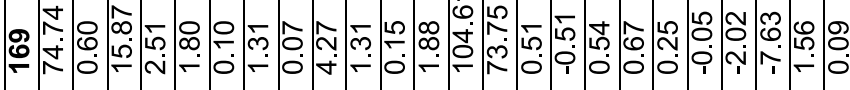

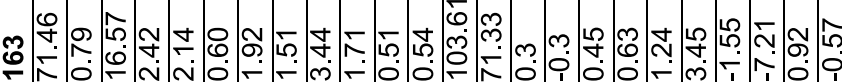
d-

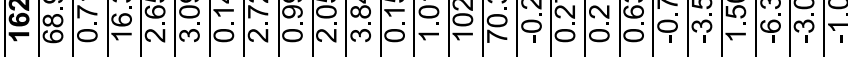

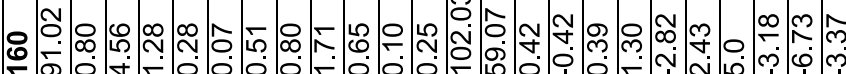

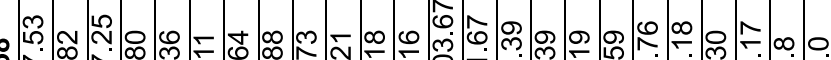

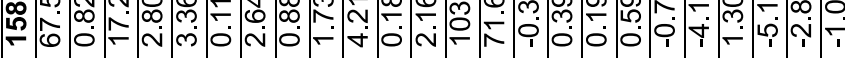
象

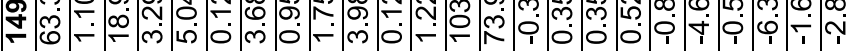

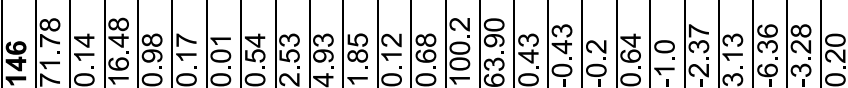

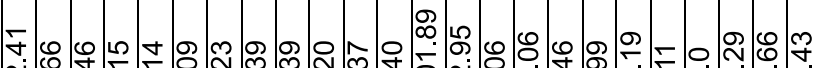

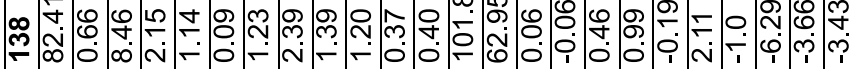
กํ.

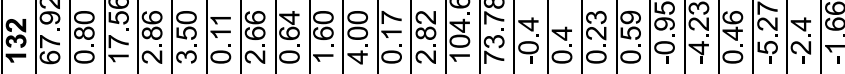

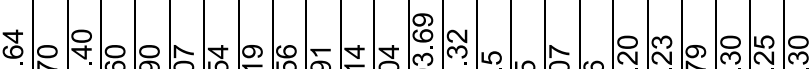

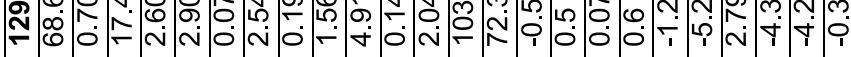

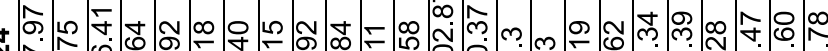

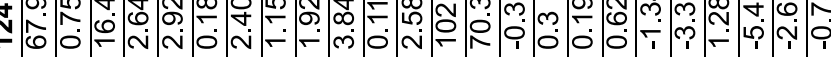

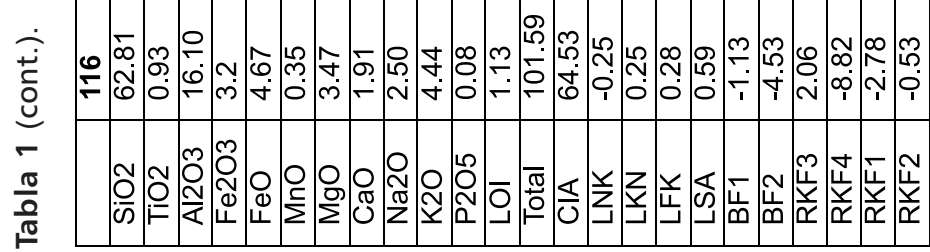



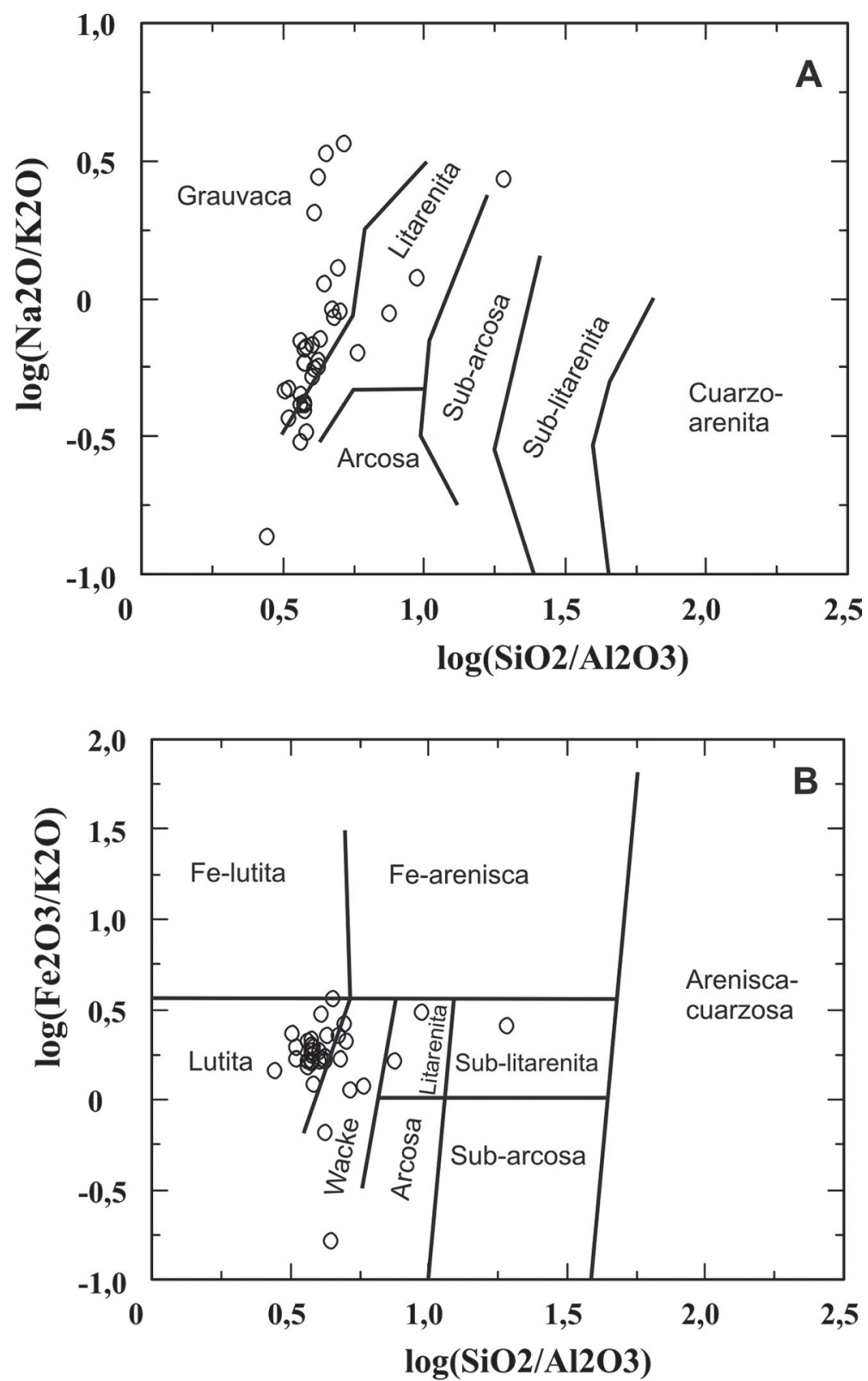

Fig. 4. A: Diagrama de clasificación $\log \log \left(\mathrm{Na}_{2} \mathrm{O} / \mathrm{K}_{2} \mathrm{O}\right)$ vs. $\log \left(\mathrm{SiO}_{2} / \mathrm{Al}_{2} \mathrm{O} 3\right)$ de psamitas y pelitas de la Formación Puncoviscana (Pettijhon et al., 1972), con los campos módificados por Herron (1988): Las muestras se concentran en los campos de grauvacas y litarenitas B: En el diagrama de Herron (1988) usando $\log \left(\mathrm{Fe}_{2} \mathrm{O}_{3} / \mathrm{K}_{2} \mathrm{O}\right)$ vs. $\log \left(\mathrm{SiO}_{2} / \mathrm{Al}_{2} \mathrm{O}_{3}\right)$, las muestras se concentran en los campos de lutitas, waques y litarenitas.

\section{INTERPRETACIÓN GEOQUÍMICA DE LAS ÁREAS DE PROVENIENCIA}

Para considerar las áreas de proveniencia se utilizó la composición química de las rocas que integran la Formación Puncoviscana, las cuales fueron interpretadas sobre la base de diagramas geoquímicos discriminantes tradicionales, que utilizan tanto a los elementos mayores, menores y trazas, como así también a relaciones entre elementos. 
Tabla 2. Contenidos en elementos trazas de la Formación Puncoviscana, en las sierras citadas. UCC = Promedio corteza continental superior (Rudnick y Gao, 2003).

\begin{tabular}{|l|l|l|l|l|l|l|l|l|l|l|l|l|l|l|l|l|l|l|}
\hline & $\mathbf{0 0 2}$ & $\mathbf{0 3 1}$ & $\mathbf{0 4 4}$ & $\mathbf{0 5 1}$ & $\mathbf{0 5 2}$ & $\mathbf{0 5 7}$ & $\mathbf{0 5 8}$ & $\mathbf{0 6 6}$ & $\mathbf{0 7 0}$ & $\mathbf{0 7 1}$ & $\mathbf{0 8 5}$ & $\mathbf{0 9 0}$ & $\mathbf{0 9 2}$ & $\mathbf{0 9 3}$ & $\mathbf{0 9 7}$ & $\mathbf{1 0 2}$ & $\mathbf{1 0 3}$ & $\mathbf{U C C}$ \\
\hline $\mathrm{Ba}$ & 960 & 1059 & 423 & 852 & 340 & 718 & 290 & 440 & 1382 & 622 & 1136 & ${ }^{*} 5^{*}$ & 658 & 884 & 902 & 1113 & 452 & 628 \\
\hline $\mathrm{Rb}$ & 154 & 164 & 212 & 107 & 193 & 217 & 173 & 200 & 55 & 184 & 120 & 138 & 155 & 217 & 142 & 147 & 187 & 82 \\
\hline $\mathrm{Sr}$ & 138 & 105 & 81 & 133 & 123 & 60 & 88 & 112 & 468 & 184 & 298 & 259 & 165 & 124 & 304 & 127 & 114 & 320 \\
\hline $\mathrm{Y}$ & 78 & 72 & 55 & 81 & 76 & 57 & 50 & 71 & 97 & 95 & 135 & 106 & 90 & 116 & 177 & 89 & 105 & 21 \\
\hline $\mathrm{Zr}$ & 191 & 66 & 130 & 480 & 140 & 138 & 119 & 141 & 146 & 124 & 294 & 239 & 312 & 156 & 902 & 214 & 133 & 193 \\
\hline $\mathrm{Pb}$ & 15 & 22 & 17 & 6 & 24 & 36 & 60 & 56 & 17 & 28 & 53 & 22 & 20 & 24 & 45 & 39 & 18 & 7 \\
\hline $\mathrm{Ga}$ & 12 & 10 & 22 & 12 & 27 & 19 & 30 & 20 & 15 & 20 & 20 & 10 & 17 & 21 & 14 & 21 & 15 & 22 \\
\hline $\mathrm{Zn}$ & 127 & 124 & 135 & 140 & 181 & 134 & 152 & 194 & 134 & 230 & 293 & 140 & 222 & 264 & 251 & 188 & 209 & 110 \\
\hline $\mathrm{Cu}$ & 2 & 27 & 36 & 18 & 9 & 32 & 23 & 3 & 23 & 13 & 36 & 32 & 19 & 9 & 36 & 10 & 2 & 30 \\
\hline $\mathrm{Ni}$ & 9 & 12 & 8 & 10 & 3 & 7 & 2 & 3 & 10 & 7 & 5 & 7 & 8 & 11 & 8 & 5 & 13 & 50 \\
\hline $\mathrm{V}$ & 54 & 155 & 84 & 17 & 92 & 24 & 47 & 81 & 240 & 71 & 86 & 933 & 60 & 27 & 41 & 138 & 51 & 99 \\
\hline $\mathrm{Cr}$ & 23 & 4 & 50 & 29 & 112 & 50 & 83 & 103 & 14 & 89 & 98 & 71 & 69 & 41 & 73 & 99 & 49 & 70 \\
\hline $\mathrm{Co}$ & 31 & 8 & 50 & 128 & 143 & 33 & 36 & 73 & 4 & 116 & 111 & 5 & 151 & 86 & 523 & 63 & 236 & 24 \\
\hline
\end{tabular}

Tabla 2 (cont.).

\begin{tabular}{|l|l|l|l|l|l|l|l|l|l|l|l|l|l|l|l|l|l|l|l|}
\hline & $\mathbf{1 0 8}$ & $\mathbf{1 1 6}$ & $\mathbf{1 2 4}$ & $\mathbf{1 2 9}$ & $\mathbf{1 3 2}$ & $\mathbf{1 3 8}$ & $\mathbf{1 4 6}$ & $\mathbf{1 4 9}$ & $\mathbf{1 5 8}$ & $\mathbf{1 6 0}$ & $\mathbf{1 6 2}$ & $\mathbf{1 6 3}$ & $\mathbf{1 6 9}$ & $\mathbf{1 7 1}$ & $\mathbf{1 7 2}$ & $\mathbf{1 7 4}$ & $\mathbf{1 7 5}$ & $\mathbf{1 / 9}$ & $\mathbf{1 8 9}$ \\
\hline $\mathrm{Ba}$ & 564 & 292 & 730 & 799 & 409 & 108 & 1082 & $\mathbf{7 0 2}$ & 584 & 946 & 442 & 1074 & 36 & 703 & $\mathbf{7 0 4}$ & 625 & $\mathbf{7 8 4}$ & 108 & 596 \\
\hline $\mathrm{Rb}$ & 155 & 193 & 148 & 213 & 184 & 74 & 86 & 252 & 191 & 61 & 198 & 107 & 75 & 171 & 253 & 206 & 200 & 189 & 180 \\
\hline $\mathrm{Sr}$ & 281 & 128 & 93 & 62 & 100 & 129 & 646 & 173 & 83 & 143 & 89 & 368 & 105 & 122 & 85 & 35 & 141 & 91 & 133 \\
\hline & 70 & 66 & 56 & 71 & 49 & 76 & 103 & 90 & 72 & 233 & 92 & 122 & 79 & 72 & 70 & 63 & 104 & 92 & 69 \\
\hline $\mathrm{Zr}$ & 162 & 143 & 165 & 137 & 93 & 954 & 109 & 243 & 141 & 4.22 & 129 & 290 & 184 & 172 & 130 & 121 & 176 & 105 & 179 \\
\hline $\mathrm{Pb}$ & 20 & 22 & 30 & 21 & 22 & 41 & 44 & 31 & 39 & 20 & 33 & 8 & 11 & 28 & 21 & 27 & 20 & 17 & 40 \\
\hline $\mathrm{Ga}$ & 23 & 22 & 26 & 20 & 20 & 4 & 10 & 27 & 16 & 3 & 18 & 8 & 21 & 21 & 25 & 17 & 18 & 19 & 22 \\
\hline $\mathrm{Zn}$ & 180 & 176 & 134 & 157 & 134 & 49 & 2 & 270 & 157 & 301 & 238 & 125 & 128 & 165 & 187 & 137 & 217 & 217 & 166 \\
\hline $\mathrm{Cu}$ & 1 & 17 & 13 & 3 & 12 & 53 & 98 & 11 & 17 & 66 & 35 & 9 & 5 & 11 & 7 & 21 & 5 & 3 & 14 \\
\hline $\mathrm{Ni}$ & 2 & 4 & 2 & 2 & 4 & 25 & 27 & 5 & 6 & 22 & 2 & 20 & 3 & 0 & 5 & 6 & 11 & 12 & 1 \\
\hline $\mathrm{V}$ & 109 & 113 & 135 & 23 & 80 & 344 & 724 & 246 & 26 & 148 & 50 & 185 & 90 & 63 & 46 & 87 & 85 & 54 & 50 \\
\hline $\mathrm{Cr}$ & 101 & 109 & 74 & 97 & 107 & 75 & 84 & 218 & 219 & 35 & 160 & 32 & 65 & 103 & 73 & 61 & 54 & 55 & 101 \\
\hline $\mathrm{Co}$ & 57 & 70 & 91 & 42 & 63 & 590 & 15 & 126 & 88 & 1019 & 233 & 90 & 16 & 83 & 51 & 86 & 104 & 184 & 25 \\
\hline
\end{tabular}

La proveniencia de los materiales, que constituyen a dichas rocas sedimentarias, permite interpretar la evolución geológica así como el ambiente tectónico que controló el desarrollo de la cuenca de Puncoviscana en la región de las sierras de Palermo, Cachi y Molinos, asimismo en rocas de Cuesta del Obispo .en el sector norte de las Cumbres Calchaquíes. En todos los casos se utiliza la información geológica-geoquímica, además de la mineralogía y petrografía. Los datos integrados indican que las rocas en general, reflejan la composición de las áreas de aporte y que han sido poco afectadas por factores tales como selección del material, alteración y metamorfismo, como se verá más adelante.

Los estudios de la edad y caracteres morfológicos de los circones detríticos contenidos en distintas secuencias sedimentarias de la Formación Puncoviscana, realizadas entre otros por Miller et al. (2010); Adams et al. (2008a, b, 2009); Aceñolaza et al. (2010), y Toselli et al. (2017a, b), permiten interpretar que los mismos proceden de rocas del Paleo-, Meso- y Neo-Proterozoico, que son correlacionables con terrenos aflorantes en Brasil, Paraguay y también del borde del cratón del Río de la Plata, tomando como apoyo que las paleo-corrientes indican proveniencias esencialmente desde el E y NE, pero sin descartar las proveniencias desde el Oeste, como las determinadas por Ježek (1990).

En razón que las rocas presentan cierta transformación de los minerales constituyentes, se cuantificó la misma mediante el «Índice de alteración química» (CIA = relación molar $\left[\left(\mathrm{Al}_{2} \mathrm{O}_{3} / \mathrm{Al}_{2} \mathrm{O}_{3}+\mathrm{CaO}+\mathrm{Na}_{2} \mathrm{O}+\mathrm{K}_{2} \mathrm{O}\right) \star 100\right]$ de Nesbitt y Young (1982). En el histograma CIA, más del $90 \%$ de las muestras dan valores entre $60 \%$ y $80 \%$ con un máximo en $72 \%$ (Fig. $5 \mathrm{~A}$ ) en base a los datos de la Tabla 1. Este índice valora la 


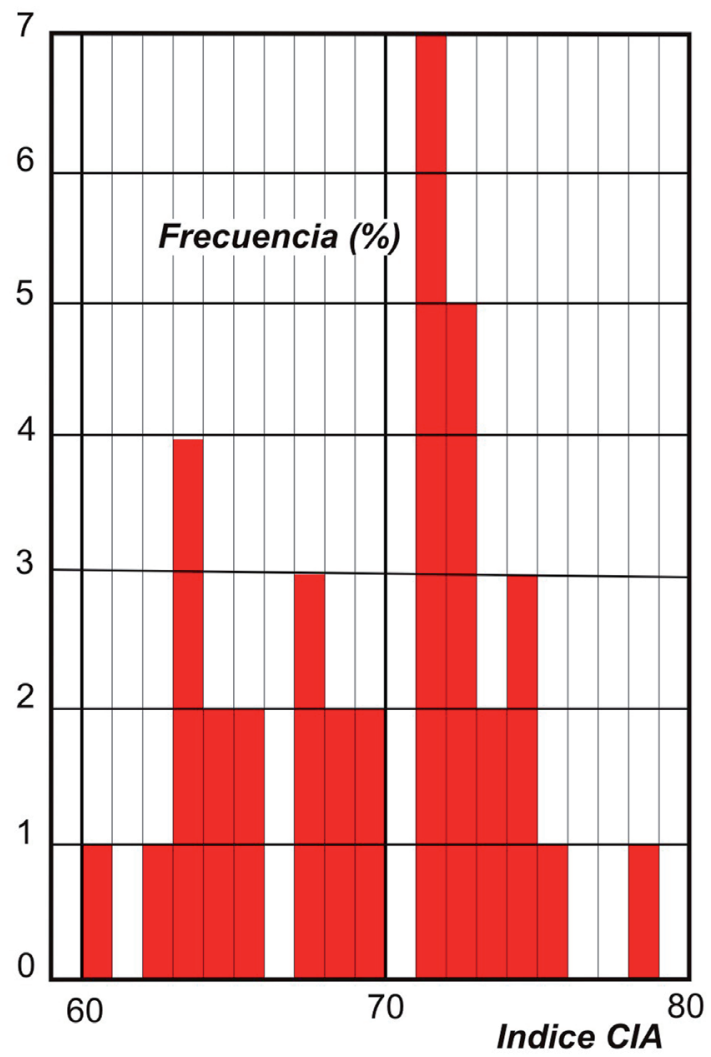

A

B

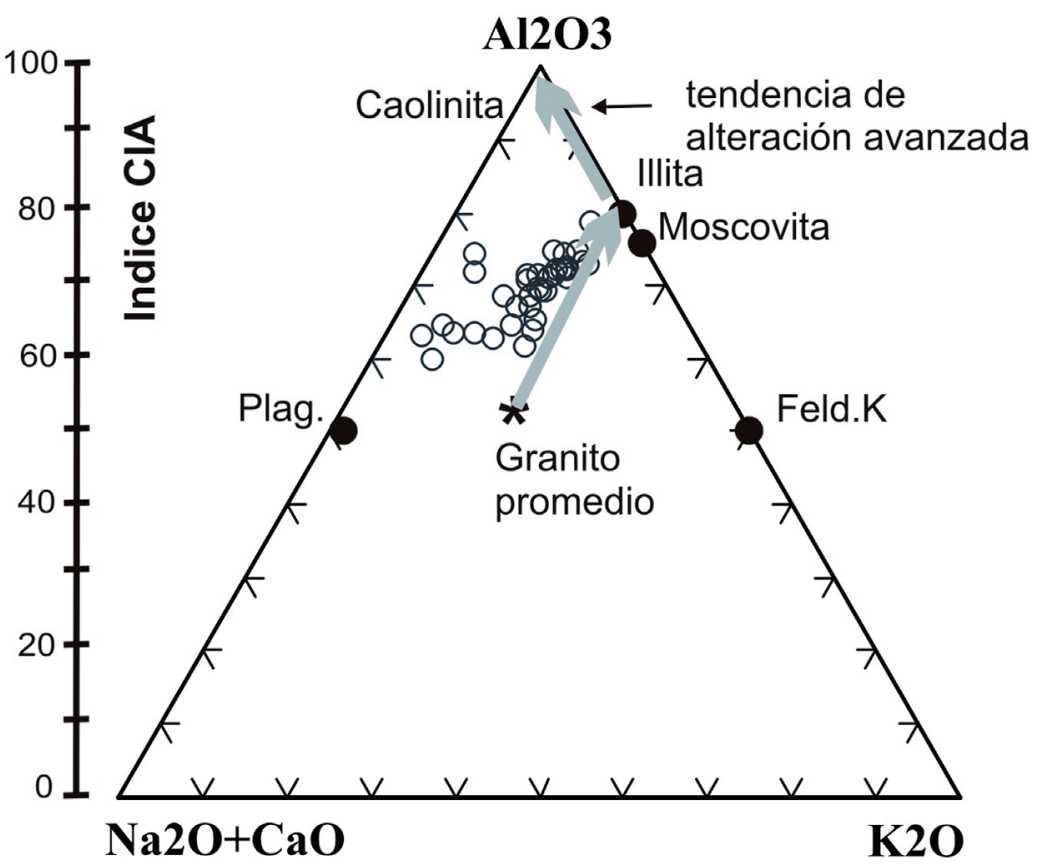

Fig. 5. A: Índice de Alteración Química (CIA) vs. Frecuencia (\%) según Nesbitt y Young (1984), más del $90 \%$ de las rocas estudiadas se proyectan entre los valores de 60 y $80 \%$, con un máximo de $72 \%$. B: En el diagrama triangular $\left(\mathrm{Na}_{2} \mathrm{O}+\mathrm{CaO}\right)-\mathrm{Al}_{2} \mathrm{O}_{3}-\mathrm{K}_{2} \mathrm{O}$ (expresado en proporciones moleculares) de Nesbitt y Young (1989), las rocas presentan una tendencia de alteración avanzada de las plagioclasas de los granitoides hacia la illita. También se proyectan las composiciones de plagioclasas, feldespato potásico, moscovita, caolinita e illita. Símbolos: Estrella: granito promedio. Circulo: Formación Puncoviscana. 
alteración de feldespatos y vidrio volcánico a minerales arcillosos, la cual también está controlada por las condiciones climáticas durante el transporte.

Dicha alteración también es evaluada en el diagrama triangular $\mathrm{Al}_{2} \mathrm{O}_{3}-\mathrm{CaO}+$ $\mathrm{Na}_{2} \mathrm{O}-\mathrm{K}_{2} \mathrm{O}$ (Fig. 5 B) de Nesbitt y Young (1984, 1989), que integra al índice CIA, con la evolución geoquímica que sufren los sedimentos. Las rocas de la Formación Puncoviscana se alinean según una tendencia que se desvía ligeramente de la correspondiente a la alteración de las rocas ácidas de la corteza, que causa el incremento de potasio durante la diagénesis, transformando a los minerales aluminosos, en illita. Diferentes desviaciones de las tendencias ideales, que son paralelas al lado del triángulo $\left(\mathrm{Al}_{2} \mathrm{O}_{3}-\mathrm{CaO}+\mathrm{Na}_{2} \mathrm{O}\right)$, estaría indicando la mezcla de diferentes fuentes, afectadas diferencialmente por la alteración y la movilización de los álcalis. Este diagrama también apoya la hipótesis de que los sedimentos provienen de rocas que se corresponden con las composiciones de la Corteza Continental Superior (UCC), lo que permite interpretar que los sedimentos de la Formación Puncoviscana han tenido un transporte sedimentario relativamente breve sin procesos mayores de reciclaje, que no permitió la maduración del material, ni la alteración avanzada, caracteres que son coherentes con las condiciones de una cuenca de antepaís.

Mediante el diagrama ortogonal de Roser y Korsch (1988) se pudo establecer la litología de las áreas de proveniencia de los sedimentos, combinando la «función discriminante $3=\left(30,638 \mathrm{TiO}_{2} / \mathrm{Al}_{2} \mathrm{O}_{3}-12,541 \mathrm{Fe}_{2} 03\right.$ (totai) $/ \mathrm{Ai}_{2} \mathrm{O3}+7,329 \mathrm{MgO} / \mathrm{AI}_{2} \mathrm{O}_{3}$ $\left.+12,031 \mathrm{Na}_{2} \mathrm{O} / \mathrm{Al}_{2} \mathrm{O}_{3}+35,402 \mathrm{~K}_{2} \mathrm{O} / \mathrm{Al}_{2} \mathrm{O}_{3}-6,382\right)$, versus el discriminante $4=(56,500$ $\mathrm{Ti}_{2} / \mathrm{Al}_{2} \mathrm{O}_{3}-10,879 \mathrm{Fe}_{2} 0_{3}$ (total) $/ \mathrm{AI}_{2} 0_{3}+30,875 \mathrm{Mg} / \mathrm{Al}_{2} 0_{3}-5,404 \mathrm{Na}_{2} 0 / \mathrm{Al}_{2} 0_{3}+11,112$ $\mathrm{K}_{2} \mathrm{O} / \mathrm{AI}_{2} \mathrm{O}_{3}-3,89$ )». Esta permite establecer que provendrían, en su mayoría, de sedimentos cuarzosos y de rocas ígneas félsicas e intermedias (Fig. 6A). Mientras que en el siguiente diagrama, también de Roser y Korsch (1988) se determinan las áreas de proveniencia combinando la Función discriminante $1=\left(-1,773 \mathrm{TiO}_{2}+0,607 \mathrm{Al}_{2} \mathrm{O}_{3}+\right.$ $\left.0,76 \mathrm{Fe}_{2} \mathrm{O}_{3} \mathrm{~T}-1,5 \mathrm{MgO}+0,616 \mathrm{CaO}+0,509 \mathrm{Na}_{2} \mathrm{O}-1,224 \mathrm{~K}_{2} \mathrm{O}-9,09\right)$, versus la función discriminante $2=0,445 \mathrm{TiO}_{2}+0,07 \mathrm{Al}_{2} \mathrm{O}_{3}-0,25 \mathrm{Fe}_{2} 0_{3} \mathrm{~T}-1,142 \mathrm{MgO}+0,438 \mathrm{CaO}+$ $\left.1,475 \mathrm{Na}_{2} \mathrm{O}+1,426 \mathrm{~K}_{2} \mathrm{O}-6,861\right)$. Aquí queda claro que los sedimentos provendrían esencialmente de rocas sedimentarias cuarzosas e ígneas félsicas (Fig. 6B).

\section{INTERPRETACIÓN GEOQUÍMICA DEL AMBIENTE DE DEPOSICIÓN}

Además de los caracteres texturales de los sedimentos que integran esta formación se utilizaron diagramas geoquímicos para interpretar el ambiente de deposición.

Bhatia (1983) utiliza las relaciones $\mathrm{Fe}_{2} \mathrm{O}_{3} \mathrm{~T}+\mathrm{MgO}$ versus $\mathrm{Al} 2 \mathrm{O} 3 / \mathrm{SiO} 2$, ambos expresados en \% en peso, para expresar la variación en la madurez mineralógica, que es evidenciada por el enriquecimiemiento en cuarzo o por la disminución de los fragmentos líticos, feldespatos y micas (illita, clorita, biotita), (Fig. 7A). Cuando la correlación de valores es positiva, indica mayor contenido de minerales lábiles con más alta relación A12O3/SiO2 y permite clasificar a las rocas en los campos de «Arco Oceánico a Arco Continental y Margen Continental Activo». En esta interpretación el autor utilizó como patrón de comparación con las turbiditas de Australia. Asimismo, 


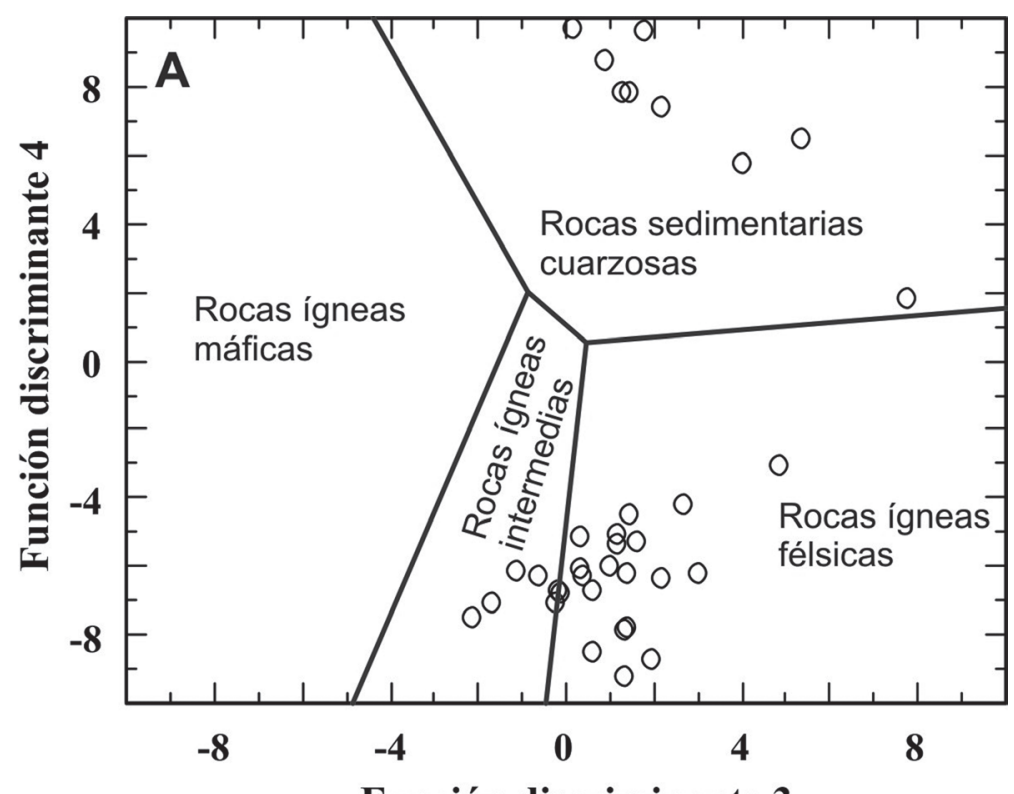

Función discriminante 3

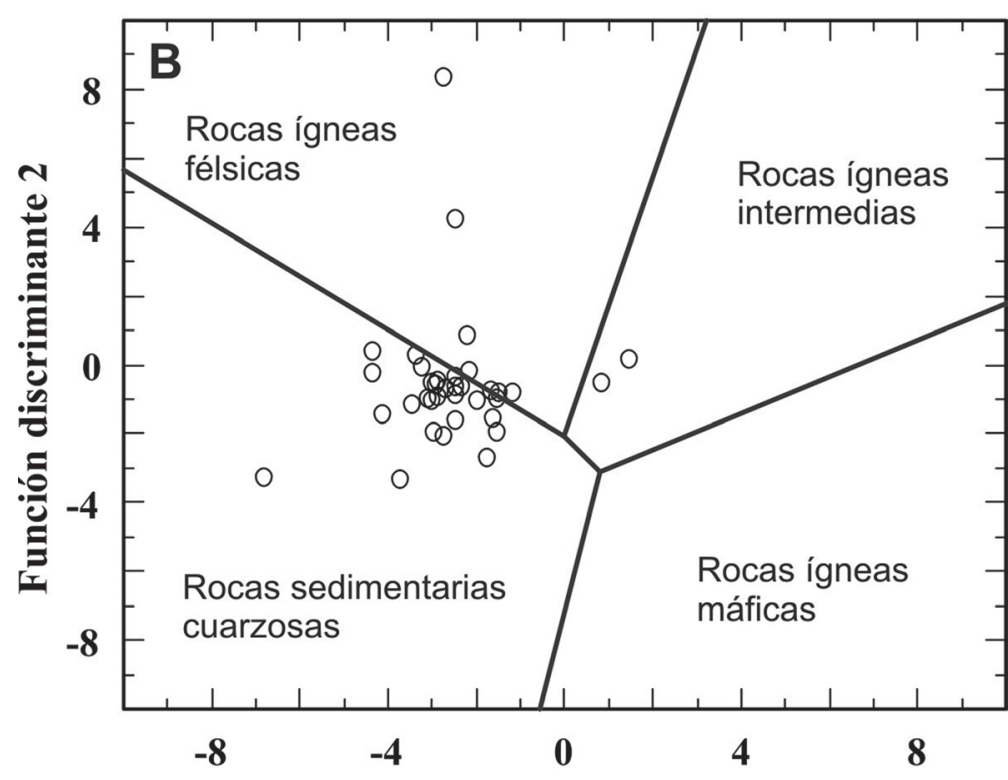

Función discriminante 1

Fig. 6. A: Funciones discriminantes 3 y 4 de Roser y Korsch (1988), para establecer la proveniencia de areniscas y lutitas, las cuales se distribuyen entre rocas sedimentarias cuarzosas y rocas ígneas félsicas e intermedias. B: Funciones discriminantes 1 y 2 (de los mismos autores) para establecer la proveniencia de areniscas y lutitas, las cuales se distribuyen entre rocas sedimentarias cuarzosas y rocas ígneas félsicas e intermedias (ver en el texto los detalles de las funciones utilizadas).

en el diagrama $\mathrm{TiO}_{2}$ versus $\mathrm{Fe}_{2} \mathrm{O}_{3} \mathrm{~T}+\mathrm{MgO}$, expresados en peso \% (Fig. 7B), muestra que las rocas se proyectan en los campos que corresponden a: Arco Continental, con pasajes a Arco Oceánico y Margen Continental Activo (Bhatia, 1985).

Otra evaluación del ambiente de deposición también puede lograrse mediante los parámetros propuestos por Bhatia (1983) utilizando la «función discriminante $1=$ 
(-0,0447 $\mathrm{SiO}_{2}-0,972 \mathrm{TiO}_{2}+0,008 \mathrm{Al}_{2} \mathrm{O}_{3}-0,267 \mathrm{Fe}_{2} \mathrm{O}_{3}+0,208 \mathrm{FeO}-3,082 \mathrm{MnO}+$ $\left.0,140 \mathrm{MgO}+0,195 \mathrm{CaO}+0,719 \mathrm{Na}_{2} \mathrm{O}-0,032 \mathrm{~K}_{2} \mathrm{O}+7,510 \mathrm{P}_{2} \mathrm{O}_{5}+0,303\right)$ versus la función discriminante $2=\left(-0,421 \mathrm{SiO}_{2}+1,988 \mathrm{TiO}_{2}-0,526 \mathrm{Al}_{2} \mathrm{O}_{3}-0,551 \mathrm{Fe}_{2} \mathrm{O}_{3}-1,610\right.$ $\mathrm{FeO}+2,720 \mathrm{MnO}+0,881 \mathrm{MgO}-0,907 \mathrm{CaO}-0,177 \mathrm{Na}_{2} \mathrm{O}-1,840 \mathrm{~K}_{2} \mathrm{O}+7,244 \mathrm{P}_{2} \mathrm{O}_{5}$ $+43,57)$ ». Estos muestran que los sedimentos se proyectan en los campos de Margen Continental Activo y Arco de Islas Continentales (Fig. 8).

Por su parte, Roser y Korsch (1986), interpretan el ambiente tectónico de deposición, mediante el diagrama que utiliza las relaciones logarítmicas de $\mathrm{K}_{2} \mathrm{O} / \mathrm{Na}_{2} \mathrm{O}$ versus el \% de $\mathrm{SiO}_{2}$ (Fig. 9), los datos analíticos se proyectan en el campo de Arco de Islas, descartando que se trate de margenes Continentales Activos o Pasivos.
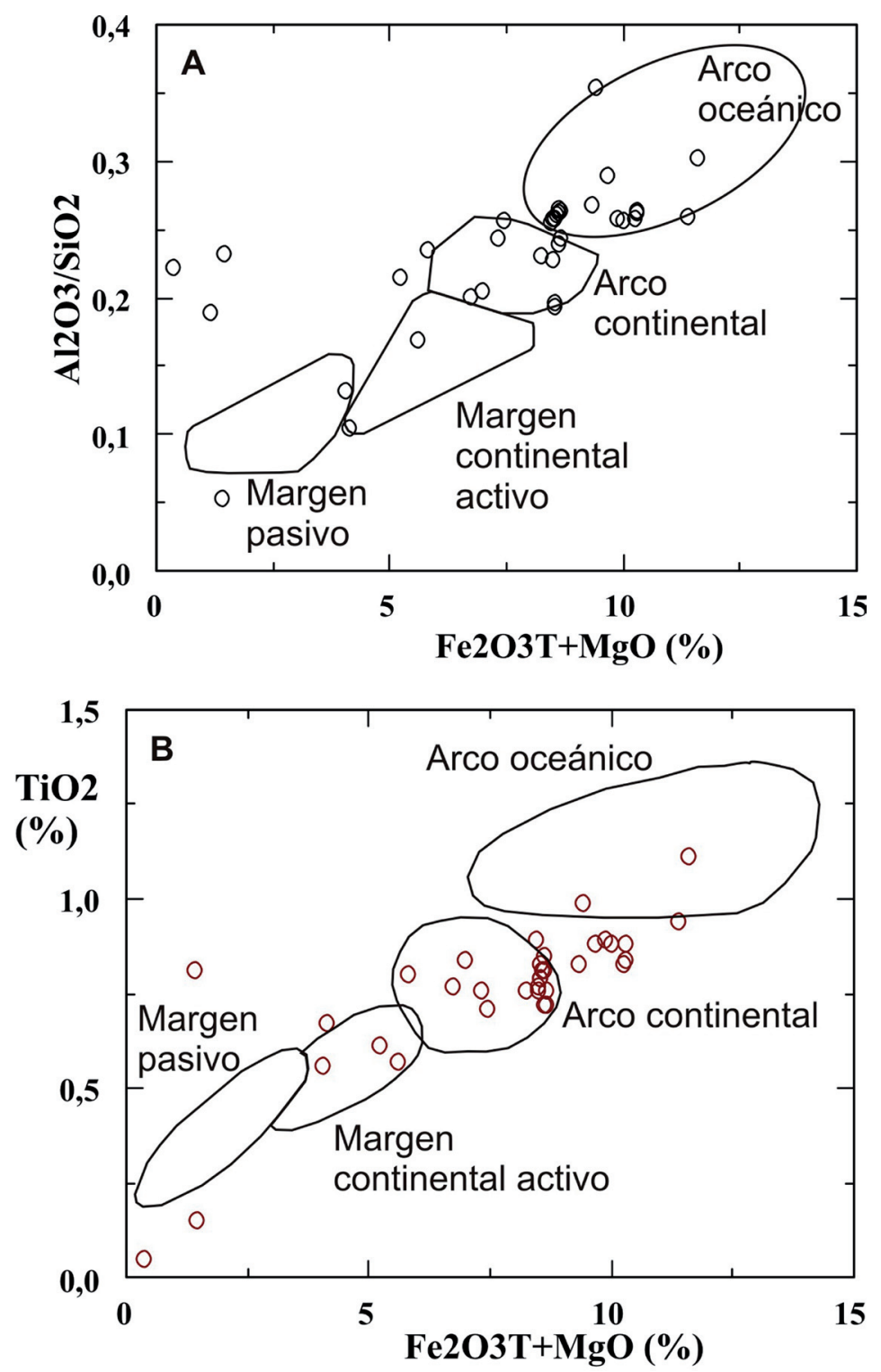

Fig. 7. Diagramas de discriminación para areniscas de Bhatia (1983). A: Relaciones $\mathrm{Al}_{2} \mathrm{O}_{3} / \mathrm{SiO}_{2}$ vs. $\mathrm{Fe}_{2}$ $\mathrm{O}_{3}+\mathrm{MgO} \%$, en el cual los valores se proyectan en los campos correspondientes a arcos oceánico y continental, siendo raras las de margen continental activo. B: Relaciones $\mathrm{TiO}_{2} \%-\mathrm{Fe}_{2} \mathrm{O}_{3}+\mathrm{MgO}$ $\%$, en este diagrama las muestras se proyectan en los campos de "Arco Continental y Margen Continental Activo», con algunos valores en «Arco Oceánico». 


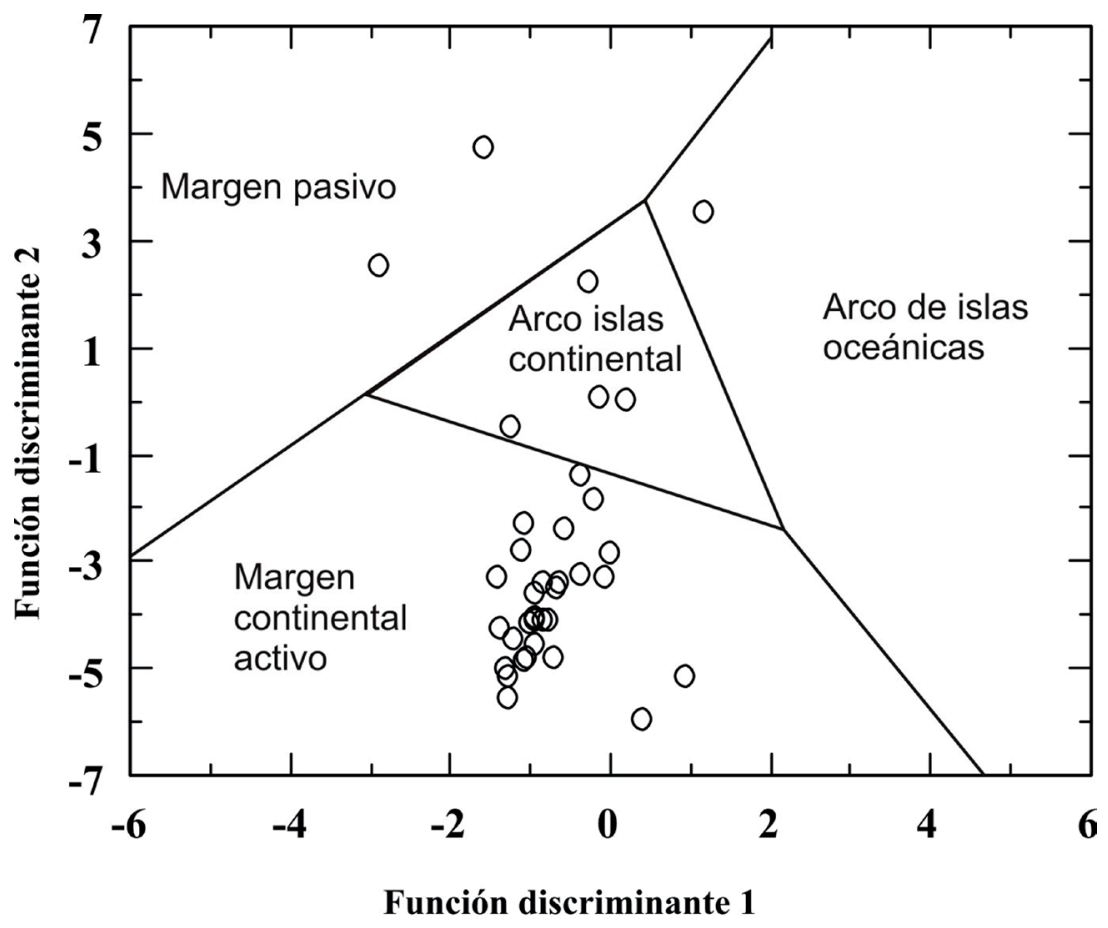

Fig. 8. Diagrama de discriminantes 1 y 2 para areniscas (Bhatia, 1983). Las muestras se proyectan en el campo de «Margen Continental Activo, con algunos valores en "Arco de Islas Continentales». (Ver en el texto los detalles de las funciones utilizadas).

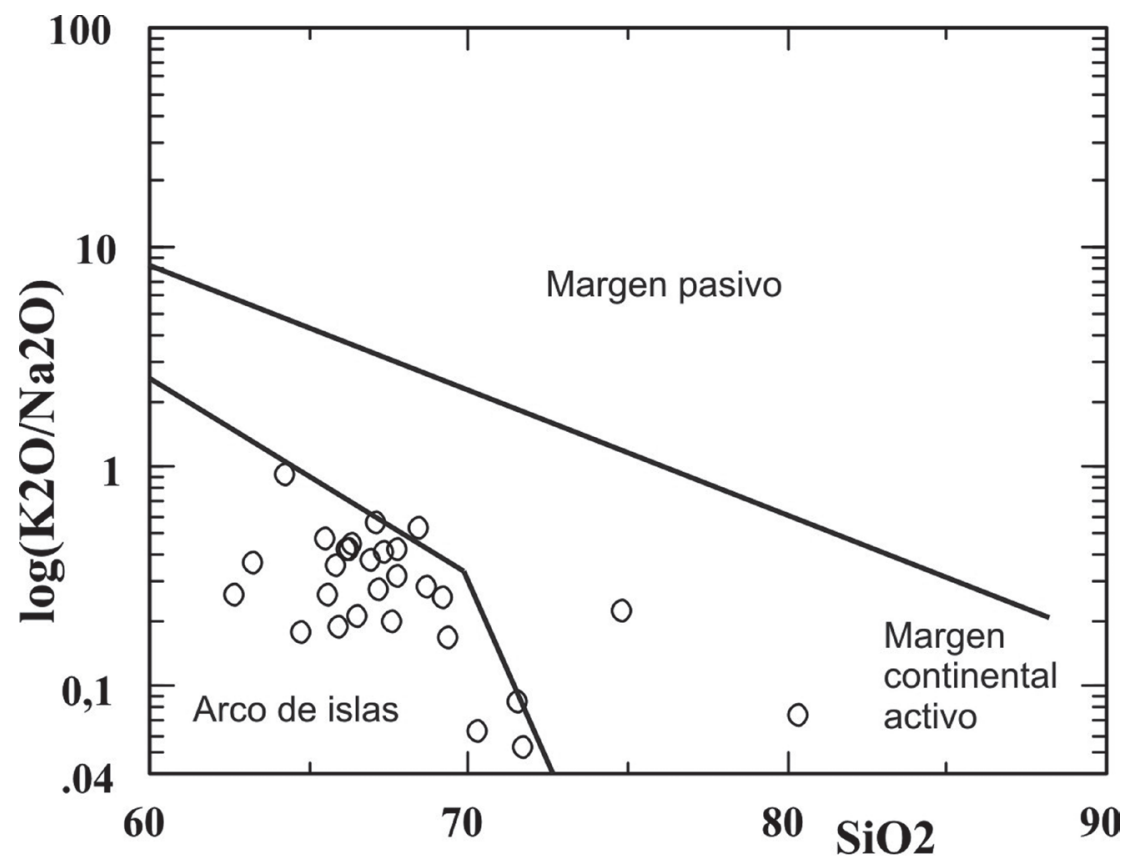

Fig. 9. Diagrama de discriminación log $\left(\mathrm{K}_{2} \mathrm{O} / \mathrm{Na}_{2} \mathrm{O}\right)$ versus $\mathrm{SiO}_{2}$ (Roser y Korsch, 1986) para suites de areniscas y lutitas. Las valores se proyectan en el campo de «Arco de Islas». 


\section{CONTENIDO FOSILÍFERO Y SU SIGNIFICADO CRONOLÓGICO}

En diversos afloramientos de las sierras de la Cordillera Oriental se encuentran asociaciones de icnofósiles, como Nereites saltensis que son asignados al Ediacarano superior y de Oldhamia radiata que se asigna al Terreneuviano, los cuales muestran compatibilidad cronoestratigráfica con los datos radimétricos que aquí se presentan y que corresponden a los 560-530 Ma. Dicho de otra forma, se pone en evidencia que es compatible la posición estratigráfica que determina la icnofauna con la geocronología (Aceñolaza y Aceñolaza, 2005; Aceñolaza y Toselli, 2010; Aceñolaza, 2012).

Obviamente la tectónica Tilcárica (Cámbrico entre Series 2 y 3) ha plegado y fracturado a la Formación Puncoviscana, de tal manera que a pesar de los numerosos estudios realizados no se ha logrado aún establecer fehacientemente las secuencias estratigráficas y sus espesores.

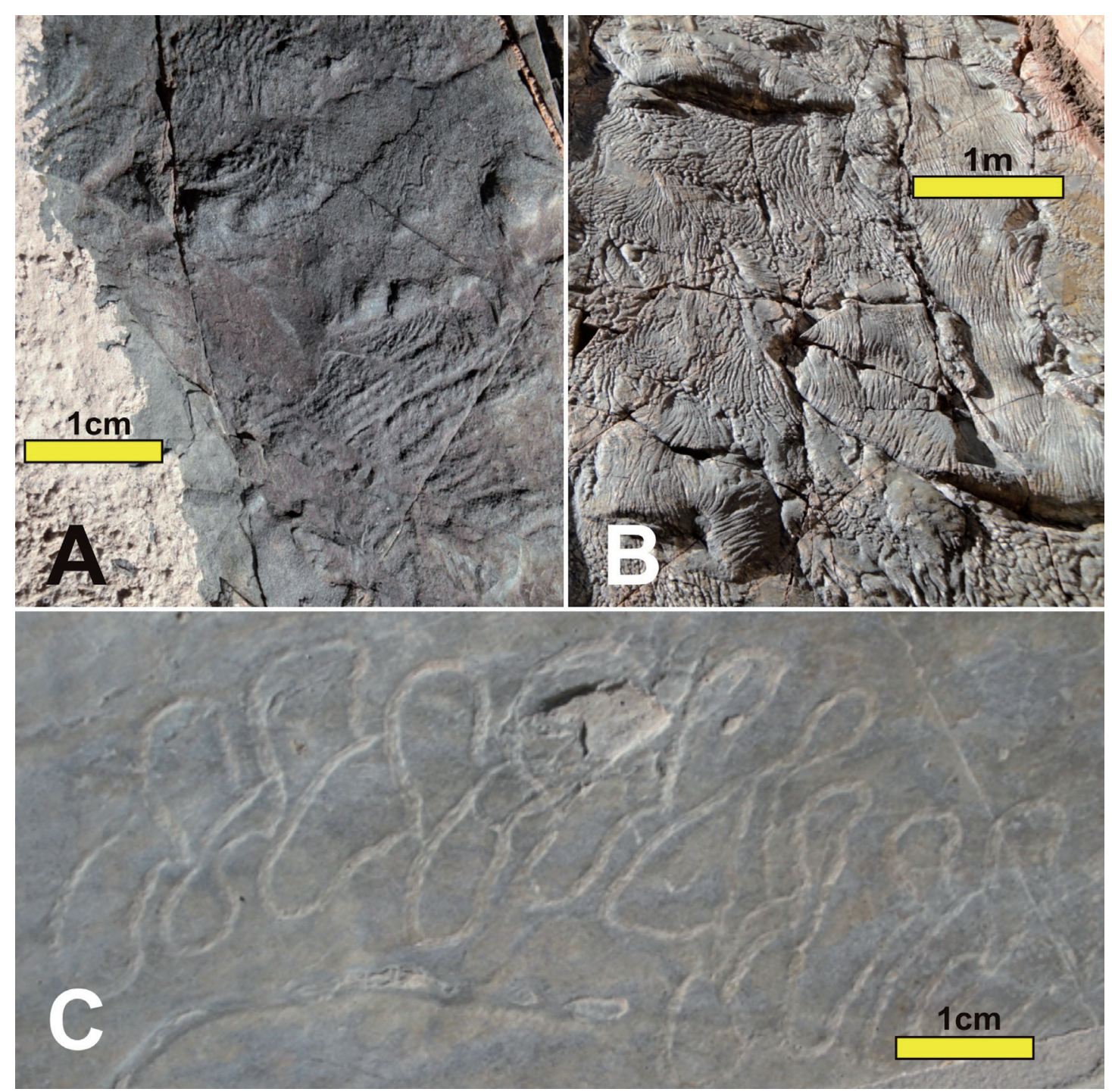

Fig. 10. Imágenes de las trazas fósiles identificadas en las sierras de Cachi y Palermo. A: Rangeomorphos, S., afin a Primocandelabrum sp. B: Estructura algal. C: Nereites saltensis. Las barras indican las escalas correspondientes. 
La presencia de Nereites saltensis en la zona de Cachi permitió correlacionar a los puntos donde esta traza fósil se encuentra, con Campo Quijano y sierra de Mojotoro (en la provincia de Salta), dentro de los estratos de la Formación Puncoviscana. En estos afloramientos está acompañada por otros icnofósiles tales como Helminthoidicnites tenuis, Achaeonassa fosulata, Cochlichnus anguineus, y Thalassinoides sp. (Aceñolaza, 2012) (Fig. 10).

En los afloramientos de la quebrada de Palermo son frecuente trazas de tipo "Wrinkle», que están junto a una estructura algal en los sedimentos depositados en una plataforma marina «intertidal» (López de Azarevich et al. (2012). Por debajo de las capas algales se localizan niveles con Vendobiontes-rangeomorfos de morfología afín a Primocandelabrum $s p$. que aparece junto a Torrowangea $s p$. y son representativos del Ediacarano alto, mientras que por debajo se encuentran niveles con Nereites saltensis.

Hay que destacar que Primocandelabrum ha sido reconocida, en el mundo, en capas cuya antigüedad está entre 579 y $550 \mathrm{Ma}$. Este fósil que se encuentra en Australia, Canadá, Rusia e Inglaterra es mencionado por primera vez para Sudamérica por Aceñolaza (2012).

\section{METODOLOGÍAS ISOTÓPICAS Y SUS IMPLICANCIAS}

Para reconstruir la historia de los eventos tectono-metamóficos de las rocas del basamento pre-Andino del NO de Argentina y ajustar su secuencia, fue fundamental la adecuada selección del material a procesar, utilizando rocas consideradas representativas de las localidades seleccionadas de la región. Sobre ellas se aplicaron en un principio las metodologías $\mathrm{K}-\mathrm{Ar}$, Rb-Sr y relaciones de ${ }^{87} \mathrm{Sr} /{ }^{86} \mathrm{Sr}$, cuyos valores varían entre 0,71275 y 0,71327. Estos datos apoyan la interpretación de diferentes fuentes para los sedimentos y los fundidos anatécticos, aunque algunos de los resultados obtenidos muestran distorsiones que indicarían pérdidas en los sistemas isotópicos, como lo muestran los resultados obtenidos por Halpern y Latorre (1973); Borrello (1969, 1971); Galliski (1983); Damm et al. (1986); Adams et al. (1989, 1990).

Para ajustar el cuadro geológico regional de la Formación Puncoviscana, se procesaron muestras de circón y monacita de las meta-sedimentitas y de las zonas de metamorfismo de contacto de los intrusivos de las localidades de La Paya, Seclantas, El Alto, Las Pampitas, Rancagua, cuyos caracteres morfológicos más representativos fueron caracterizados por Lork et al. (1989), mediante imágenes obtenidas con el microscopio electrónico de barrido (RAM) (Fig. 11) y sus edades fueron establecidas mediante los diagramas isotópicos. Las dataciones se hicieron sobre circones de diferentes tipos y orígenes, desde euhedrales y homogéneos, a polifásicos y redondeados por transporte sedimentario. También se presentan corroídos y recristalizados con bordes de crecimiento, además de presentar inclusiones, coloraciones variadas y en algunos casos núcleos relícticos. Asimismo, el comportamiento isotópico suele variar con la granulometría, por lo que las interpretaciones de edad tienen un cierto grado de incertidumbre, a lo que se agrega la influencia de diferentes procesos geológicos a los cuales han estado sometidos. 

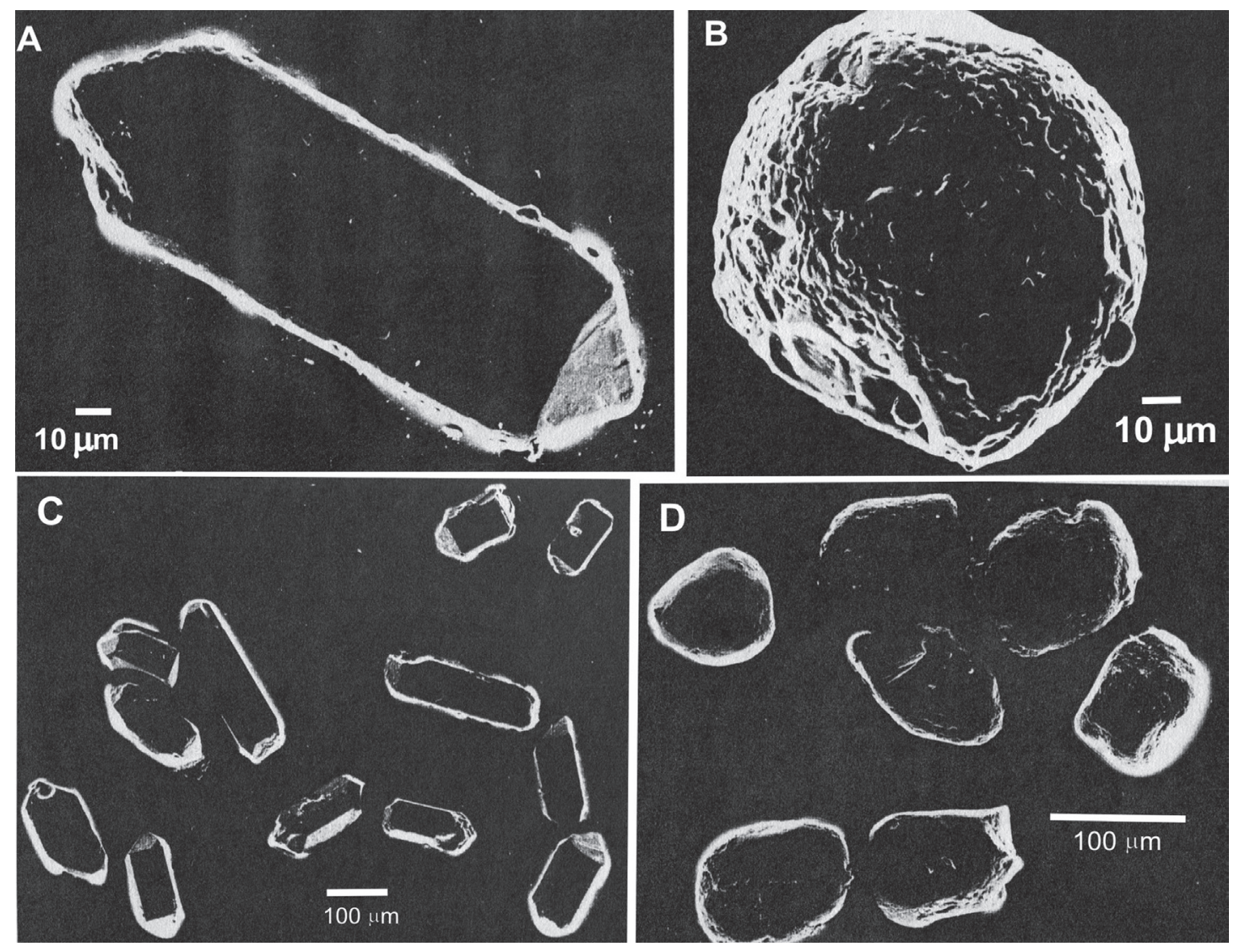

Fig. 11. Imágenes de circones detríticos obtenidas con microscopio electrónico (REM). A: Circón detrítico prismático largo, de origen volcánico, con escaso transporte sedimentario, en corneana del Granito El Alto. B: Circón detrítico redondeado por transporte sedimentario, en la corneada del Granito El Alto. C: Circones detríticos idiomorfos de la Formación Puncoviscana en la localidad de Rancagua. D: Circones detrítico redondeados por transporte sedimentario de la Formación Puncoviscana en la localidad de Rancagua.

$\mathrm{El}$ diagrama concordia-discordia evidencia que las relaciones ${ }^{206} \mathrm{~Pb} / 238 \mathrm{U}$ versus $207 \mathrm{~Pb} / 235 \mathrm{U}$ correspondientes a circones detríticos de la Formación Puncoviscana, marca el punto de intersección de la discordia promedio, resultante de dos curvas de regresión definidas por circones tanto euhedrales como redondeados y de diferentes colores (rosados, grises y marrones) determinando una edad de $583 \mathrm{Ma}$, indicando el rejuvenecimiento sufrido por el efecto térmico del intrusivo de Rancagua (Fig. 12A). Un fenómeno similar se observa con las discordias definidas por los circones euhedrales prismáticos largos, integrados con otros redondeados y con colores marrones y grises, que generan un punto de intersección de las curvas en $527 \mathrm{Ma}$, en la localidad de La Paya, la cual estaría indicando la edad máxima de sedimentación de la Formación Puncoviscana (Fig. 12B). Estos valores resultan del promedio de edades más antiguas, correspondientes a los núcleos de los circones y de las capas de crecimiento periféricas, formadas durante el último evento térmico.

En la Figura 13 se presenta el diagrama concordia de la localidad de Seclantas, con las relaciones ${ }^{206} \mathrm{~Pb} /{ }^{238} \mathrm{U}$ vs. ${ }^{207} \mathrm{~Pb} / 235 \mathrm{U}$ y con las elipses de error para diferentes granulometrías de circones volcánicos encontrados en la Formación Puncoviscana, que han sido tratados con $\mathrm{HNO}_{3}$, manteniendo las edades originales de los mismos. 

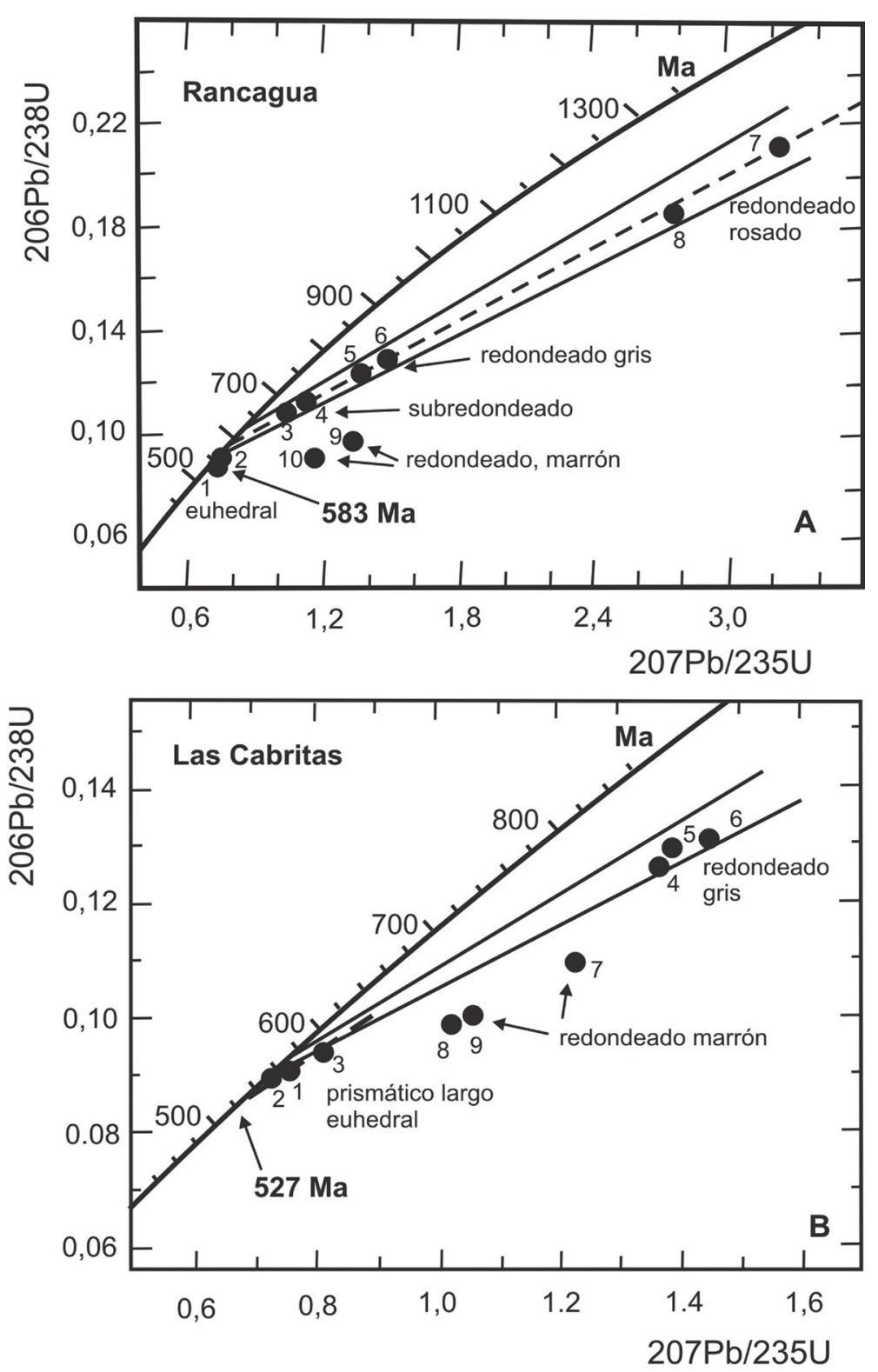

Fig. 12. Diagrama concordia-discordia de relaciones ${ }^{206} \mathrm{~Pb} /{ }^{238} \mathrm{U}$ versus ${ }^{207} \mathrm{~Pb} /{ }^{235} \mathrm{U}$ correspondientes a circones detríticos de la Formación Puncoviscana. A: Intersecciones de las curvas discordia, formadas por circones euhedrales y redondeados de colores rosado, gris y marrón, con la concordia en 583 Ma, en la localidad de Rancagua. B: Curva discordia generada por circones prismáticos largos, junto a otros redondeados de colores gris y marrón, con intersección de la concordia en 527 Ma, en la zona de Las Cabritas.

El diagrama concordia desarrolla una línea utilizando circones detríticos cogenéticos, con diferentes caracteres, contenidos en una corneana, sometida a metamorfismo de contacto en La Paya, muestra una línea de correlación coherente de los circones que definen una intersección de la discordia en $520 \mathrm{Ma}$ (Fig. 14A, Tabla 3). Asimismo, el diagrama concordia definido por circones del granidoide El Alto, muestra una muy buena correlación de la línea de discordia que es definida por tres poblaciones de circones que produce una intersección a $530 \mathrm{Ma}$. Por su parte las diferentes monacitas claras y turbias dan $465 \mathrm{Ma}$, para el granito (Fig. 14-B, Tabla 3). 


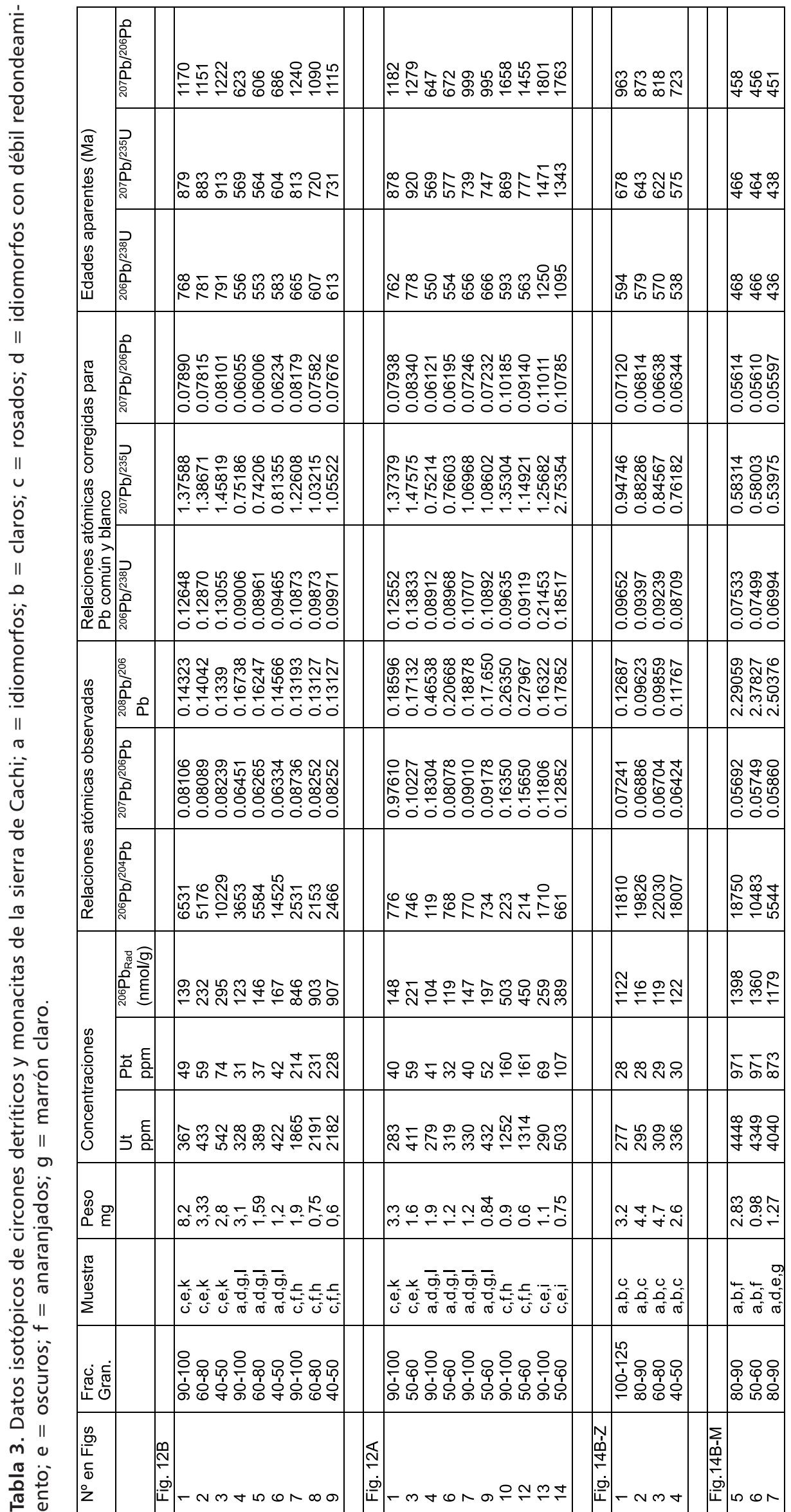




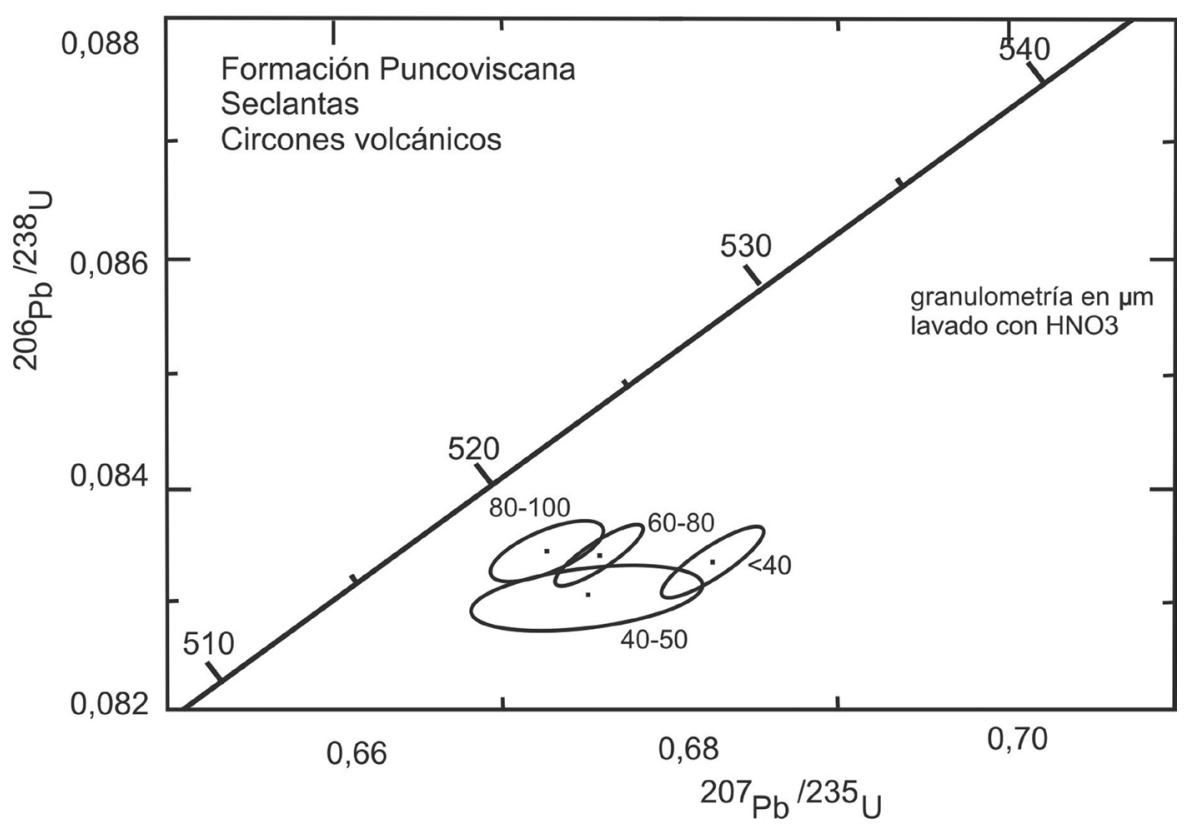

Fig. 13: Elipses de error en el diagrama concordia ${ }^{206} \mathrm{~Pb} /{ }^{238} \mathrm{U}$ vs. ${ }^{207} \mathrm{~Pb} /{ }^{235} \mathrm{U}$ obtenidos en circones volcánicos con diferentes caracteres y granulometrías, contenidos en las rocas de la Formación Puncoviscana, tratados con $\mathrm{HNO}_{3}$, en la localidad de Seclantas.

También se incluyen como elementos de comparación, a los circones detríticos de las rocas del basamento meta-sedimentario de Cuesta del Obispo, como región de la Formación Puncoviscana no afectada por intrusiones ígneas. En el diagrama de relaciones ${ }^{206} \mathrm{~Pb} /{ }^{238} \mathrm{U}$ vs. ${ }^{207} \mathrm{~Pb} /{ }^{235} \mathrm{U}$, se obtiene una edad de intersección del campo de discordia de aproximadamente $500 \mathrm{Ma}$ ? (Fig. 15).

\section{CONSIDERACIONES GEOLÓGICAS Y METODOLÓGICAS}

Las rocas sedimentarias metamorfizadas que constituyen el basamento de las sierras de Palermo, Cachi, Molinos y Cuesta del Obispo se han depositado durante el Ciclo Pampeano.

Los datos isotópicos indican que los circones de la Formación Puncoviscana, asimilados por los fundidos anatécticos, sólo se disuelven o reaccionan parcialmente debido al corto tiempo de residencia en el fundido, por lo que no pueden reequilibrarse totalmente y sólo suelen desarrollar sobre-crecimientos y.el resto de los cristales se mantienen como meta-estables dentro de las rocas ígneas y metamórficas de mayor grado.

Dadas las incertidumbres que presenta la metodología U-Pb convencional aplicada en circones y con el fin de poder ajustar las edades de los eventos sedimentarios y metamórficos en la Cordillera Oriental, se aplicaron técnicas complementarias sobre las relaciones $\mathrm{U}-\mathrm{Pb}$ de los circones, como cátodo-luminiscencia, que permite contrastar su confiabilidad y detectar relictos antiguos que suelen conservar su cristalografía y química original. Las monacitas son las que mejor definen las edades 

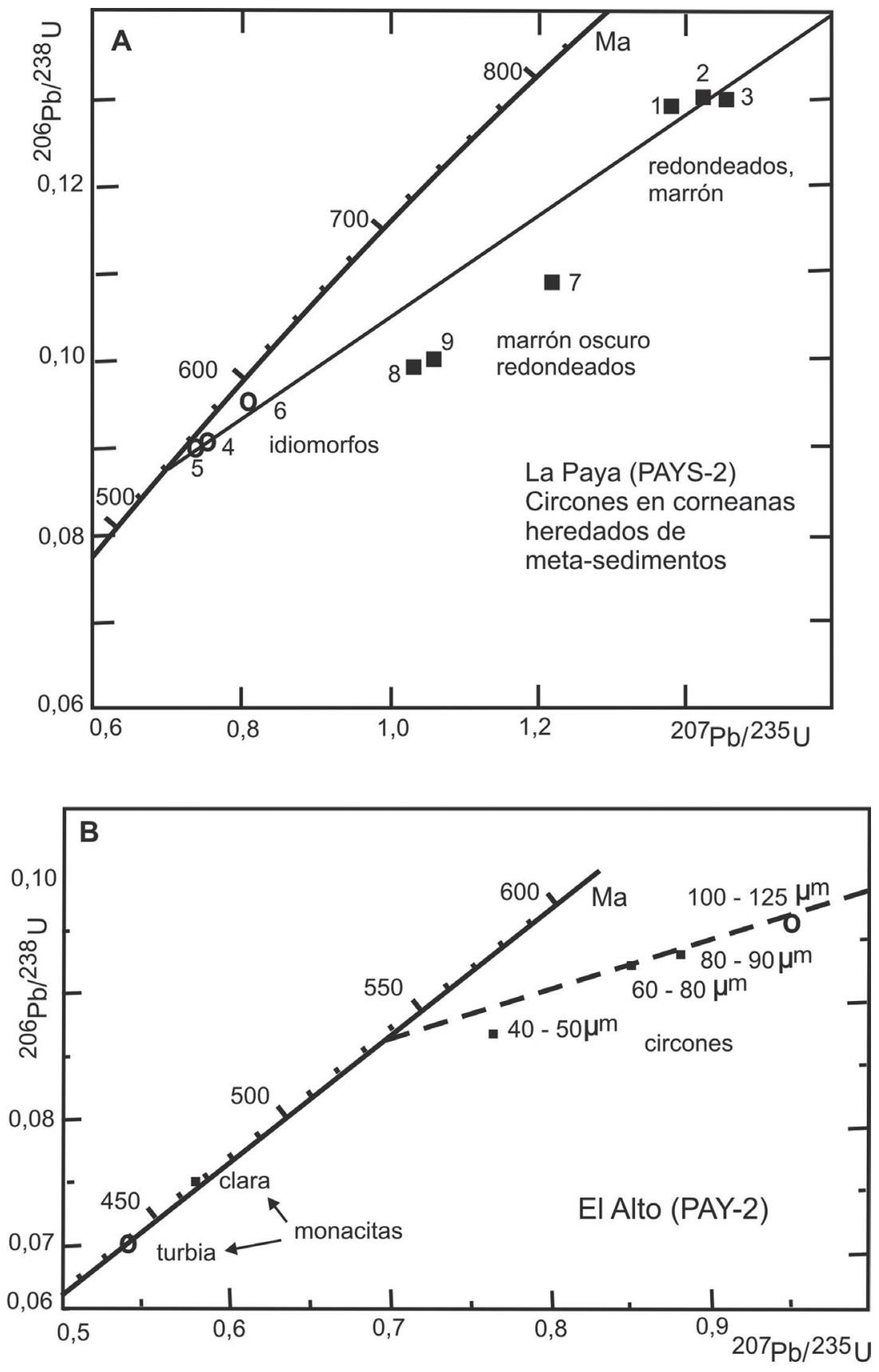

Fig. 14. A: Diagrama concordia para circones detríticos cogenéticos, con diferentes caracteres, contenidos en una corneana, sometida a metamorfismo de contacto en La Paya. La línea de correlación de los circones definen una intersección de la discordia en 520 Ma (Tabla 3). B: Diagrama concordia para circones y monacitas del granidoide El Alto. La mejor correlación de la discordia se da por tres poblaciones de circones que produce una intersección a $530 \mathrm{Ma}$. En tanto las diferentes monacitas claras y turbias dan $465 \mathrm{Ma}$, para el granito (Tabla 3).

y permiten identificar las fases orogénicas a las que pertenecen los intrusivos. Asimismo, el uso de las relaciones $\mathrm{Rb}-\mathrm{Sr}$ en roca total, ayuda en la interpretación de su significado geológico, en base a las relaciones iniciales de sus isótopos.

En afloramientos de la Formación Puncoviscana de la sierra de Santa Victoria, Escayola et al. (2011) identifican niveles de tobas con caracteres calco-alcalinos es- 


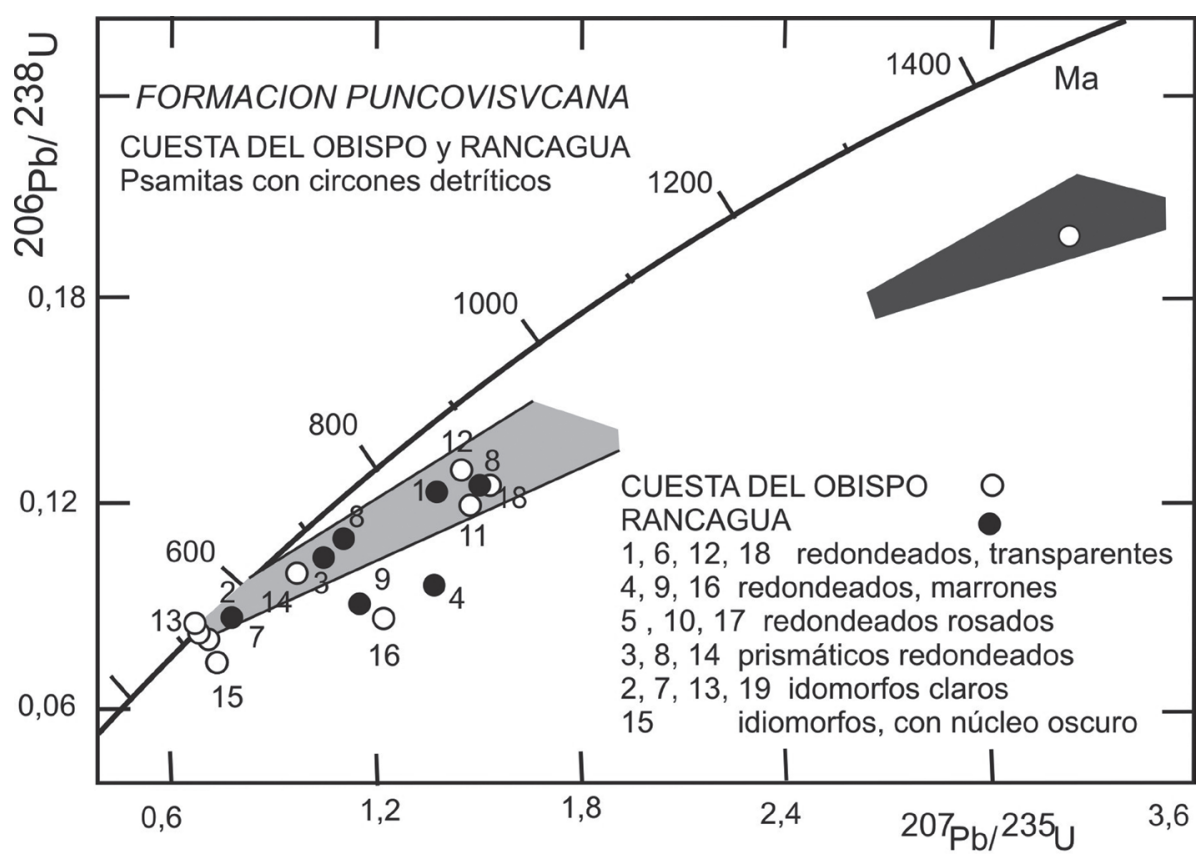

Fig. 15. Diagrama concordia-discordia entre ${ }^{206} \mathrm{~Pb} /{ }^{238} \mathrm{U}$ vs. ${ }^{207} \mathrm{~Pb} /{ }^{235} \mathrm{U}$ mostrando el campo de los circones detríticos obtenidos en psamitas de la Formación Puncoviscana en Cuesta del Obispo y Rancagua. Las diferentes tipologías y granulometrías utilizadas no muestran variación, en la proyección de la intersección, entre ambos ambientes.

tableciendo edades U-Pb en circones mediante TIMS y SHRIMP entre 540 y 523 $\mathrm{Ma}$, valores que son coherentes con los que aquí obtenemos.

Generalmente, como ocurre en la zona de Rancagua, en la trondhjemita Aguas Calientes y en el álcali-granito post-tectónico de La Paya, los circones detríticos provenientes de la Formación Puncoviscana, incluidos en las zonas de techo y de borde de los intrusivos, así como en las corneanas que los rodean, muestran escasa o nula transformación por el evento térmico, aun cuando se los observe mediante técnicas de cátodo-luminiscencia, lo que indicaría un período relativamente corto de calentamiento con. rápido enfriamiento. Por su parte los circones sedimentarios incluidos en las migmatitas que rodean al intrusivo Las Pampitas, si bien mantienen las formas originales de los cristales, desarrollan sobre-crecimientos inducidos por el evento térmico más prolongado a que han estado sometidos y que necesitan para su. desarrollo este tipo de rocas.

La estrecha relación entre las edades isotópicas obtenidas y los niveles con ichno-fósiles correspondientes a las zonas de Nereites saltensis y Oldhamia radiata, permiten un ajuste preciso de las edades de sedimentación de la Formación Puncoviscana (Fig. 16).

Es bien sabido que el techo de la formación se encuentra en el Cámbrico, entre las Series 2 y 3, correspondiendo a la posición de la discordancia Tilcárica, mientras que su piso, con dudas, se ubica en el período Criogeniano próximo a la base del Ediacarano y se lo designa como Ancajano ( $583 \mathrm{Ma})$.

Los procesos de sedimentación, deformación y plutonismo más antiguos asociados con la Cuenca de Puncoviscana, tienen lugar en el Terreneuviano y se reacti- 


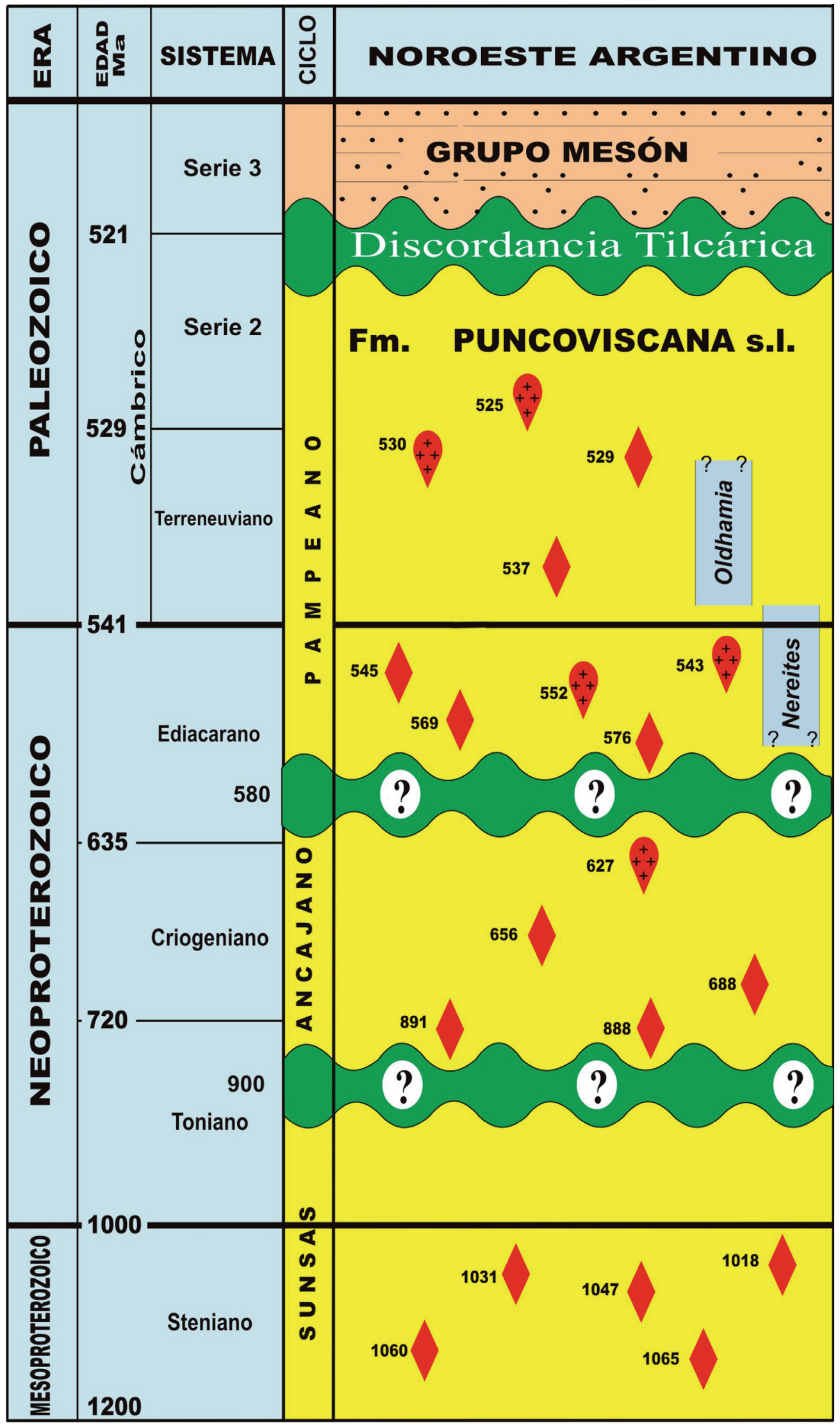

Fig. 16. Cuadro estratigráfico de referencia de la Formación Puncoviscana, con las edades isotópicas $\mathrm{U}-\mathrm{Pb}$ y su correlación con los niveles de Nereites saltensis y Oldhamia radiata. 
van con el cierre de la cuenca que marca el cierre del Ciclo Pampeano, relacionado probablemente con la actividad de la placa paleo-Pacífica y la colisión del terreno Arequipa-Antofalla con el margen oeste de Gondwana. La secuencia meta-sedimentaria se deforma con el desarrollo de pliegues abiertos y clivaje de plano axial en los niveles pelíticos, con metamorfismo de Facies Sub-esquistos Verdes a Esquistos Verdes (Willner, 1990), los cuales producen re-cristalización de la matriz y la orientación planar de las micas. Esto tiene lugar por procesos metamórfico-deformativos sin-, tardío- y post-cinemáticos, cuyos picos térmicos se corresponden con los plutones tonalítco-trondhjemíticos y granodioríticos-graníticos del Ciclo Famatiniano.

En algunas áreas del basamento de Sierras Pampeanas, como por ejemplo en la Sierra de Quilmes, se alcanzan condiciones de alto grado metamórfico, aunque no es fácil determinar donde los eventos ígneo-metamórficos corresponden a la orogenia Tilcárica, o son debidos a eventos orogénicos y metamórficos acaecidos durante el Ciclo Famatiniano (sensu Aceñolaza y Toselli, 1976).

\section{CONCLUSIONES}

Las rocas que constituyen la Formación Puncoviscana en las sierras de Palermo, Cachi y Molinos, están representadas esencialmente por grauvacas, litarenitas, lutitas y wackes, como se desprende de las clasificaciones químicas de Pettijohn et al. (1972) y Herron (1988). Las cuales son coherentes con las observaciones petrográficas y las composiciones mineralógicas.

Las técnicas de difracción de rayos-X, aplicadas a los minerales arcillosos, especialmente a la fracción $<2 u m$ de la illita, da valores de cristalinidad relativa entre 120 y 360, que corresponde al campo de Facies Sub-esquistos Verdes o Anquimetamorfismo y que sólo localmente alcanza la Facies Esquistos Verdes.

El Índice de alteración química (CIA) muestra un pico de frecuencia de 72 con una dispersión entre 60 y 80 . Asimismo, en el triángulo $\mathrm{Na}_{2} \mathrm{O}+\mathrm{CaO}-\mathrm{K}_{2} \mathrm{O}-\mathrm{Al}_{2} \mathrm{O}_{3}$ se muestra un grado de alteración que va desde la composición del granito promedio a la illita.

Con respecto a la composición de las áreas de proveniencia los distintos diagramas geoquímicos indican composiciones entre rocas ígneas félsicas y sedimentarias cuarzosas, que son típicas de la corteza continental superior.

Las condiciones de deposición, interpretadas a partir de los caracteres sedimentológicos y geoquímicos, indican un mar somero correspondiente a un arco de islas continental en transición a un margen continental activo, como lo corroboran los diagramas geoquímicos específicos.

El desarrollo localizado de depósitos de diamictitas se habrían formado en cañones submarinos que cortan a las secuencias psamo-pelíticas normales.

La investigación de los circones contenidos en la Formación Puncoviscana permite reconocer dos agrupaciones, una de origen claramente detrítico, con formas redondeadas por abrasión, provenientes de terrenos erosionados más antiguos y otra, más moderna, de origen volcanogénico de formas prismáticas y cuya zona de caída no debe estar a más de $200 \mathrm{~km}$, lo que evidencia actividad volcánica piroclástica 
desarrollada en la cuenca de deposición. Ambos grupos, que se reconocen en las corneanas y migmatitas del Complejo La Paya, mantienen gran parte de sus caracteres morfológicos originales.

En Seclantás, la Formación Puncoviscana contiene circones detríticos redondeados de $558 \mathrm{Ma}$, redondeados por abrasión durante su transporte, mientras que los circones volcaniclásticos euhedros tienen edades entre 580 y $520 \mathrm{Ma}$ (Ediacarano-Terreneuviano), siendo los más jóvenes datados de $525 \mathrm{Ma}$, en las inmediaciones de La Paya (Lork et al., 1990), que evidencia que esta sería la edad máxima de sedimentación de las rocas.

Por las características sedimentológicas y petrográficas de las rocas de la Formación Puncoviscana, se considera que fueron transportadas principalmente por corrientes de turbidez, con rápido soterramiento y sólo localmente fueron re-trabajadas en el ambiente marino. Estas características corresponden a una cuenca poco profunda, como lo evidencian las trazas fósiles y las estructuras sedimentarias encontradas (López de Azarevich et al., 2012). Una característica particular de las rocas es la homogeneidad mineralógica y textural en toda su extensión, que es típica de las cuencas pericratónicas.

Los valores isotópicos obtenidos son compatibles con la presencia de Nereites saltensis que ha sido obtenido en las zonas de Escalchi (Cachi) y río Palermo y es asignado al Ediacarano superior; mientras que la presencia de Oldhamia radiata indica niveles del Terreneuviano y aún más jóvenes.

Una importante deformación y metamorfismo de las rocas de la Formación Puncoviscana tiene lugar durante la orogenia Tilcárica con el cierre de la cuenca del Ciclo Pampeano ocurrida a los 520 Ma, la cual es más antigua que el Grupo Mesón, de edad cámbrica media a superior, que se deposita discordantemente sobre la Formación Puncoviscana, en las provincias de Jujuy, Salta, Catamarca y Tucumán.

\section{TRABAJOS CITADOS}

Aceñolaza, F. G. 2012. Biodiversity of the Ediacaran-early Cambrian transition in northwestern Argentina and related areas. Revue de Paléobiologie, Genéve, Volumen Especial 70 Aniversario Dr. Alberto Riccardi. 11: 299-309.

Aceñolaza, F. G., y Aceñolaza, G. 2005 La Formacion Puncoviscana y unidades estratigráficas equivalentes en el Neoproterozoico - Cámbrico Temprano del Noroeste Argentino. Latin American Journal of Sedimentology and Basin Analysis 12 (2): 65-87.

Aceñolaza, F. G., y Toselli, A. J., 1976. Consideraciones estratigráficas y tectónicas sobre el Paleozoico inferior del noroeste argentino. II Congreso Latino-Americano de Geología Venezuela. 2: 741-754.

Aceñolaza, F. G., Durand, F. R., Diaz Taddei, R. 1976. Geología y contenido paleontológico del basamento de la región de Cachi, Provincia de Salta, República Argentina. Actas $6^{\circ}$ Congreso Geológico Argentino, 1: 319-332. Buenos Aires. Aceñolaza F., Toselli A., 1981. Geología del Noroeste Argentino. Universidad Nacional de Tucumán, 212 p., Tucumán. 
Aceñolaza, F. G. y Toselli, A. J. 2010 The Pampean orogen: Ediacaran-Lower Cambrian evolution History of Central and Northwest region of Argentina. In: Gaucher, C., Sial, A. N., Halverson, G. P., Frimmel., H. (Eds) NeoproterozoicCambrian Tectonics Global Change and Evolution: a focus on Southwestern Gondwana. Developments in Precambrian Geology 16: 239-254.

Aceñolaza, F. G., Toselli, A. J., Miller, H., y Adams, C. 2010. Interpretación de las poblaciones de circones detríticos en unidades estratigráficas equivalentes del Ediacarani-Cámbrico de Argentina. Serie Correlación Geológica 26: 49-64.

Adams, Ch., Miller, H., y Toselli, A. J. 1989. New K-Ar ages on the metamorphic history of the Puncoviscana Formation and equivalents, NW Argentina. Zentralblatt Geologie und Paläontologisch. Teil I (5-6): 987-997.

Adams, Ch., Miller, H., y Toselli, A. J. 1990. Nuevas edades de metamorfismo por el método K-Ar de la Formación Puncoviscana y equivalentes, NW Argentina. In: Aceñolaza, F. G., Miller, H., y Toselli, A. J. (eds.). El Ciclo Pampeano en el Noroeste Argentino. Serie Correlación Geológica, 4: 209-219. Tucumán.

Adams, C., Miller, H., y Toselli, A. J. 2008a. Detrital zircon U-Pb ages of the Puncoviscana Formation. Late Neoproterozoic - Early Cambrian, NW Argentina: provenance area and maximum age of deposition. VI South American Symposium on Isotope Geology. Actas digitales.

Adams, Ch., Miller, H., Toselli, A. J., y Griffin, W. L. 2008b. The Puncoviscana Formation of northwest Argentina: U-Pb geochronology of detrital zircons and $\mathrm{Rb}-\mathrm{Sr}$ metamorphic ages and their bearing on its stratigraphic age, sediment provenance and tectonic setting. Neues Jahrbuch Geologie und Paläontologie Abhandlungen, 247 (3): 341-352.

Adams, C., Miller, H., y Toselli, A. J. 2009. Detrital zircon U-Pb ages of the Puncoviscana Formation and its metamorphic equivalents in Catamarca and $\mathrm{La}$ Rioja, northwest Argentina. In: Wörner, G., Möller-McNett, S. (Eds.) Lateinamerika-Kolloquium 2009. Abstract and Program. Universitätsverlag Göttingen, 20-21 p.

Bhatia, M. R. 1983. Plate tectonics and geochemical composition of sandstones. Journal of Geology 91 (6): 611-627. Bhatia, M.R. 1985. Composition and classification of Paleozoic flysh of eastern Australia: implication in provenance and tectonic setting interpretation. Sedimentary Geology 41(2-4): 249-268.

Bhatia, M. R., y Crook, K. A. W. 1986. Trace element characteristics of greywackes and tectonic setting discrimination of sedimentary basins. Contributions to Mineralogy and Petrology 92 (2): 181-193.

Borello, A. V. 1969. Los geosinclinales en la Argentina. Dirección Nacional de Geología, Anales 14, 189 pp.

Borello, A. V. 1971. The Cambrian of South América. In: Holland, CE. (ed.): Cambrian of the New World, 385-438. Intercience, London.

Cisterna, C. 1986. Contribución al conocimiento geológico de la región comprendida en la localidad de La Angostura, departamento San Carlos, Cordillera Oriental, provincia de Salta. Trabajo final de licenciatura. Facultad de Ciencias Naturales e Instituto Miguel Lillo. Universidad Nacional de Tucumán (inédito). 
Coira, B., Manca, N., y Chayle, W. 1990. Registros volcánicos en la Formación Puncoviscana. Serie Correlación Geológica 4: 53-60.

Damm, K. W., Pichowiak, S., y Todt, W. 1986. Geochemie, Petrologie und Geochronologie der Plutonite und des metamorphen Grundgebirges in Nordchile. Berliner Geowissenchaften Abhandlungen. (A) 66: 73-146.

Durand, F. R.,y Aceñolaza, F. G. 1990. Caracteres biofaunisticos, paleoecológicos y paleogeográficos de la Formación Puncoviscana (Precámbrico superior-Cámbrico inferior) del Noroeste Argentino. In: Aceñolaza, F. G., Miller, H., Toselli, A. J. (Eds.). El Ciclo Pampeano en el Noroeste Argentino. Serie Correlación Geológica 4: 71-112.

Durand, F. R. 1990. Los conglomerados del Ciclo Pampeano en el Noroeste Argentino. In: Aceñolaza, F. G., Miller, H., Toselli, A. J. (Eds.). El Ciclo Pampeano en el Noroeste Argentino. Serie Correlación Geológica 4: 61-69.

Durand, F. y L. Spalletti, 1986. Las facies turbidíticas del Precámbrico SuperiorCámbrico inferior en la zona de Corralito, provincia de Salta. 1 Reunión Argentina de Sedimentología. Resúmenes: 113-116.

Escayola, M. P., van Staal, C. R., Davis. W. J. 2011. The age and tectonic setting of the the Puncoviscana Formation in northwestern Argentina: An accretionary complex related to Early Cambrian closure of the Puncoviscana Ocean and accretion of the Arequipa- Antofalla block. Journal of South American Earth Sciences. 32: 438-459.

Galliski, M. A. 1983. Distrito minero El Quemado, departamento La Poma y Cachi, provincia de Salta. I: El basamento del tramo septentrional de la Sierra de Cachi. Revista de la Asociación Geológica Argentina, 38 (2): 209-224.

Galliski, M. A. y Miller C. F. 1989. Petrogénesis de las trondhjemitas de Cachi: condicionamientos impuestos por elementos de tierras raras e implicancias tectónicas. Reunión Geotransectas de América del sur, Actas 58-62, Mar del Plata.

Galliski, M. A., Toselli, A.J., Saavedra, J. 1990. Petrology and geochemistry of the Cachi high-alumina trondhjemites, northwestern Argentina. In: Kay, M. S., y Rapela, C.W. (eds.). Plutonism from Antarctica to Alaska. Geological Society of America, Special Paper 241: 91-100.

Gosen, W. von, Buggisch, W., y Prozzi, C. 2009. Provenance and geotectonic setting of Late Proterozoic-Early Cambrian metasediments in the Sierras de Córdoba and Guasayán (western Argentina): a geochemical approach. Neues Jahrbuch Geologie und Paläontologie Abhandlungen. 251/3: 257-284. Stuttgart.

Halpern, M., y Latorre, C. O. 1973. Estudio geocronológico inicial de rocas del Noroeste de la República Argentina. Revista Asociación Geológica Argentina, 28: 195-205.

Hauser, N. 2011. Petrología y geología isotópica de las rocas ígneas y estudios de proveniencia (U-Pb y Lu-Hf) de las rocas metasedimentarias del basamento del Paleozoico inferior en las áreas de Tastil, Niño Muerto, Río Blanco y Río Grande, Cordillera Oriental, Noroeste Argentino. Tesis Doctoral inédita. 248 p. Universidad Nacional de Salta. 
Herron, M. M. 1988. Geochemical classification of terrigenous sands and shales from core of $\log$ data. Journal of Sedimentary Petrology 58: 820-829.

Hongn, F. D., y Seggiaro, R. E. 2001. Hoja Geológica 2566-III, Cachi. Provincias de Salta y Catamarca. Boletín 248, 93 pp. SEGEMAR. Buenos Aires.

Ježek, P., A. P. Willner, A. P., Aceñolaza, F. G., y Miller, H. 1985. The Puncoviscana trough - a large basin of Late Precambrian to Early Cambrian age on the Pacific edge of the Brazilian shield. Geologische Rundschau 74: 573-584.

Ježek, P. 1990. Análisis sedimentológico de la Formación Puncoviscana entre Tucumán y Salta. In: Aceñolaza, F. G., Miller, H., y Toselli, A. J. (Eds). El Ciclo Pampeano en el Noroeste Argentino. Serie Correlación Geológica 4: 9-35.

Ježek, P., y Miller, H. 1986. Deposition and facies distribution of turbiditic sediments of the Puncovicana Formation (Upper Precambrian - Lower Cambrian) within the basement of the NW-Argentine Andes. Zentralblatt Geologie und Paläontologie. Teil I: 9-10: 1235-1244.

Keppie, J. D., y Bahlburg, H. 1999. Puncoviscana Formation of northwestern and central Argentina: Passive margin or foreland basin deposits? In: LaurentiaGondwana connections before Pangaea (Eds V. A. Ramos and J. D. Keppie), Geological Society of America Special Publication: 336, 139-144.

López de Azarevich, V., Aceñolaza, F. G., Aceñolaza, G. F., Omarini, R. H., Azarevich, M. 2012. La cuenca Neoproterozoica-Eocámbrica en el NOA: sedimentología y ambientes de depósito de secuencias con icnofósiles, nuevas perspectivas. XIII Reunión Argentina de Sedimentología, Relatorio, 119-132. Salta.

Lork, A., Miller, H., y Kramm, U. 1989. U-Pb zircón and monazite ages of the La Angostura granite and the orogenic history of the northwest Argentine basement. Journal of South American Earth Sciences, 2/2: 147-153.

Lork, A., y Bahlburg, H. 1993. Precise U-Pb ages of monazite from the Faja Eruptiva de la Puna Oriental and the Cordillera Oriental, NW Argentina. XII Contreso Geológico Argentino y II Congreso de Exploración de Hidrocarburos, Acta 4: 1-6. Mendoza.

Lork, A., Miller, H., Kramm, U., y Grauert, B. 1990. Sistemática U-Pb de corcones detríticos de la Formación Puncoviscana y su significado para la edad máxima de sedimentación en la Sierra de Cachi (prov. De Salta, Argentina). In: Aceñolaza, F. G., Miller, H., y Toselli, A. J. (eds.). El Ciclo Pampeano en el Noroeste Argentino. Serie Correlación Geológica, 4: 199-208. Tucumán.

Méndez, V., Nullo, F. E., Otamendi, J. 2006. Geoquímica de las Formaciones Puncoviscana y Cachi, Sierra de Cachi, Salta. Revista de la Asociación Geológica Argentina, 61 (2): 256-268.

Miller, H., Adams, C., Aceñolaza, F. G., Toselli, A. J. 2010. Ways and wrong ways of interpreting detrital zircón ages. VII South American Symposium on Isotope Geology (VII-SSAGI). Brasilia. Publicación CD-9h3028.

Mon, R., y Hongn, F. 1988. Caracterización estructural de la Formación Puncoviscana dentro del basamento del norte argentino. Revista Asociación Geológica Argentina, 43: 124-127. 
Mon, R., y Hongn, F. 1996. Estructura del basamento proterozoico y paleozoico inferior del norte argentino. Revista Asociación Geológica Argentina, 51(1): 1-10.

Mon, R., Gutiérrez, A. A., y Cisterna, C. E. 2017. Estructura de los Andes del norte Argentino y su entorno regional, 131 pp. Editorial Académica Española.

Moya, C. y Salfity, J., 1982. Los Ciclos Magmáticos en el Noroeste Argentino. Actas $5^{\circ}$ Congreso Latinoamericano de Geología, III:523-526.

Nesbitt, H. W., y Young, G. M. 1982. Proterozoic climates and plate motions inferred from major elements chemistry of lutites. Nature, 299: 715-717.

Nesbitt, H. W., y Young, G. M. 1984. Prediction of some weathering trends of plutonic and volcanic rocks based upon thermodynamic and kinetic considerations. Geochemical and Cosmochimical Acta 48: 1523-1534.

Nesbitt, H. W., y Young, G. M. 1989. Formation and diagenesis of weathering profiles. Journal Geology 97: 129-147.

Omarini, R. H., Aparicio, A., Parica, C., Pichowiak, S., Garcia, L., Damm, K. W., Viramonte, J. G., Salfity, J. A., y Alonzo, R. N. 1985. New geochronological datashed light upon Precambrian age of Puncoviscana Formation, Northwestern Argentina. Comunications.

Omarini, R.H., y Alonso, N. R. 1987. Lavas en la Formación Puncoviscana, Río Blanco, Salta, Argentina. X Congreso Geológico Argentino. Tucumán. Actas 4: 292-295.

Pettijohn, F. J., Potter, P. E., Siever, R. 1972. Sand and sandstones. Springer Verlag, New-York. Pupin, J. P. 1980.Zircon and Granite Petrology. Contributions to Mineralogy and Petrology, 73: 207-220.

Roser, B. P., y Korsch, R. J. 1986. Determination of tectonic setting of sandstonemudstone suites determined using $\mathrm{SiO} 2$ content amd $\mathrm{K} 2 \mathrm{O} / \mathrm{Na} 2 \mathrm{O}$ ratio. Journal Geology 94: 635-650.

Roser, B. P., y Korsch, R. J. 1988. Provenance signatures of sandstone-mudstone suites determined using discriminant function of major-element data. Chemical Geology 67: 119-139.

Salfity, J. A., Omarini, R. H., Baldis, B., y Gutiérrez, W. 1975. Consideraciones sobre la evolución geológica del Precámbrico y Paleozoico del norte argentine. II Congreso Iberoamericano de Geología Económica, 4: 341-361. Buenos Aires.

Schón, C. 1991. Magmenentwickung und Intrusionsgeschichte im Südteil der Sierra de Cachi, NW - Argentinien. Inaugural-Dissertation zur Erlangung des Doktorgrades der Geowissenschaftlichen Fakultát der Ludwig-MaximiliamsUniversitát München. (Tesis Doctoral).

Schón, C., y Miller, H. 1990. The evolution of the lower Paleozoic trondhjemitegranite suites SW of Cachi, NW, Argentina. Symposium International Geodinamique Andine. Colloques et Séminaires, Grenoble, France, 363-366.

Sola, A. M., Becchio, R. A., y Pimentel, M. M. 2010. Leucogranito Pumayaco:anatexis cortical durante el ciclo orogénico Famatiniano en el extremo norte de la sierra de Molinos, provincia de Salta. Revista Asociación Geológica Argentina, 66 (1-2): 206-224. 
Spalletti, L. y F. Durand, 1986. Estudio de las facies sedimentarias del basamento de la región de Corralito, provincia de Salta, Argentina. 10 Congreso Geológico Argentino Actas 1:311-314.

Toselli, A. J. y Rossi de Toselli, J. N. 1990. Metamorfismo de baja presión en las Sierras Pampeanas y Cordillera Oriental, en el NW de Argentina. Relaciones con el plutonismo granítico. XI Congreso Geológico Argentino, Acta 1: 174177. San Juan.

Toselli, A. y Rossi de Toselli, J. N. 1990b. Metamorfismo de la Formación Puncoviscana en las provincias de Salta y Tucumán, Argentina. V Congreso Latinoamericano de Geología, Acta II: 37-52. Argentina.

Toselli, A. J., Aceñolaza, G. F., y Rossi, J. N. 2017a. Evolución del basamento Neiproterozoico-Terreneuviano en la Cordillera Oriental y Sierras Pampeanas del Noroeste de Argentina. Relatorio XX Congreso Geológico Argentina, 141-165. Tucumán.

Toselli, A. J., Aceñolaza, F. G., Miller, H., y Rossi, J. N. 2017b. Áreas de proveniencia de meta-sedimentos e interpretación geoquímica de ambientes tectónicos de deposición de la Formación Puncoviscana: Cordillera Oriental y Sierras Pampeanas, Argentina. Acta geológica Lilloana, 29 (2): 87-105.

Toselli, A. J., y Weber, K. 1982.Anquimetamorfismo en rocas del Paleozoico Inferior en el Noroeste de Argentina. Acta Geológica Lilloana XVI (1): 187-200.

Turner, J. C. 1960. Estratigrafía de la Sierra de Santa Victoria y adyacencias. Boletín de la Academia Nacional de Ciencias de Córdoba, 42: 77-126.

Turner, J. C. 1972. Cordillera Oriental. In: Leanza, A.F. (ed.). Geología Regional Argentina. Academia Nacional de Ciencias de Córdoba, 117-142.

Turner, J. C., y Mon, R. 1979. Cordillera Oriental. In: Turner, J.C. (Ed.). Geología Regional Argentina. Publicación Especial Academia Nacional de Ciencias en Córdoba, 1: 57-94.

Weber, K. 1972. Kristallinität des Illits in Tonschiefern und andedere Kriterien schwacher Metamorphose im norföstlichen Rheinischen Schiefergebirge. Neues Jarhbuch Geologisch Paläontologische Abhandlungen, 141:333-363.

Willner, A. 1990. División tectonometamórfica del basamento del noroeste argentino. In: Aceñolaza, F., Miller, H., and Toselli, A. (Eds.) El Ciclo Pampeano en el Noroeste Argentino. Serie Correlación Geológica 4: 113-159.

Zimmermann, U. 2005. Provenance studies of very low-to low-grade metasedimentary rocks of the Puncoviscana Complex, northwest Argentina. In: Vaughan, A., Leat, P., y Pankhurst, R. (Eds.) Geological Society of London. Special Publication 246: 381-416. 